This item was submitted to Loughborough's Research Repository by the author.

Items in Figshare are protected by copyright, with all rights reserved, unless otherwise indicated.

\title{
Why are fiscal multipliers asymmetric? The role of credit constraints
}

PLEASE CITE THE PUBLISHED VERSION

https://doi.org/10.1111/ecca.12340

PUBLISHER

Wiley

VERSION

VoR (Version of Record)

PUBLISHER STATEMENT

This is an Open Access Article. It is published by Wiley under the Creative Commons AttributionNonCommercial 4.0 International Licence (CC BY-NC). Full details of this licence are available at: https://creativecommons.org/licenses/by-nc/4.0/

\section{LICENCE}

CC BY-NC 4.0

\section{REPOSITORY RECORD}

McManus, Richard, Gulcin Ozkan, and Dawid Trzeciakiewicz. 2020. "Why Are Fiscal Multipliers Asymmetric? the Role of Credit Constraints". Loughborough University. https://hdl.handle.net/2134/36680. 


\title{
Economica ISE
}

Economica (2021) 88, 32-69

doi:10.1111/ecca. 12340

\section{Why are Fiscal Multipliers Asymmetric? The Role of Credit Constraints}

\author{
By Richard McManus $\uparrow$, F. Gulcin OzKant and Dawid Trzeciakiewicz $\dagger \dagger$ \\ $\dagger$ Canterbury Christ Church University $\quad \ddagger$ King’s College London $\quad \dagger \dagger$ Loughborough \\ University
}

Final version received 7 February 2020.

\begin{abstract}
Recent empirical evidence strongly points to the state dependence of fiscal multipliers that are larger in recessions than in expansions. Yet standard business cycle models face great difficulty in producing such asymmetric fiscal policy effects. By incorporating endogenously binding collateral constraints into a medium scale dynamic stochastic general equilibrium model, we find that fiscal effectiveness can vary substantially across the business cycle. The key to our framework is the state-dependent nature of collateral constraints - binding in bad times while slack in good times, amplifying the effectiveness of fiscal policy and hence generating fiscal multipliers that are larger during recessions.
\end{abstract}

\section{INTRODUCTION}

Substantial fiscal stimulus packages adopted in response to the 2008-9 global financial crisis revived interest in the effectiveness of fiscal policy, particularly in downturns. A key finding from the ensuing empirical work has been that fiscal multipliers are statedependent-larger in recessions when there is spare capacity in the economy, and smaller in upturns. For example, Auerbach and Gorodnichenko (2012, 2013), Baum and Koester (2011), and Fazzari et al. (2015) find that government spending multipliers range from near zero at the peak of the business cycle to 1.6 or greater during recessions. Similarly, Tagkalakis (2008) shows that fiscal policy has been more effective in expanding private investment during recessions compared to expansions in OECD countries. Bachmann and Sims (2012) document the non-linearity in government spending multipliers, and show that this is due to governments pursuing different types of policy in upturns versus in downturns. Although other papers find smaller variation (see, for example, Owyang et al. 2013; Ramey and Zubairy 2018), there is now significant empirical support for fiscal multipliers that vary across the cycle.

Despite such widespread evidence, formal work on the state dependence of fiscal effectiveness lags behind. That is perhaps not surprising given the difficulty that standard business cycle models face in generating asymmetries in dynamics. To the best of our knowledge, there are only two attempts in the existing literature to formally answer the question of why fiscal policy is more effective in bad times. In the first, Michaillat (2014) demonstrates that the effect of fiscal expansion varies across the stages of the business cycle by utilizing a simple New Keynesian framework with search and matching employment frictions. An increase in public employment increases the tightness of the labour market and crowds out private employment; this effect is stronger in expansions (when employment is already high and the labour market tight) than in recessions, leading to the public employment multiplier doubling (from 0.24 to 0.49 ) when the unemployment rate rises from $5 \%$ to $8 \%$.

The second formal explanation for the asymmetric effects of fiscal policy is provided by Canzoneri et al. (2016), who base their state-dependent multipliers on costly financial intermediation. By incorporating countercyclical variation in bank intermediation costs 
into the model of Curdia and Woodford (2010), Canzoneri et al. (2016) arrive at fiscal multipliers that are state-dependent. In the presence of financial frictions that are aggravated in recessions, an expansionary fiscal action facilitates more borrowing by reducing the interest rate spread, which is itself countercyclical. ${ }^{1}$ This, in turn, allows fiscal policy to be more effective in expanding output in bad times than in good times. While Canzoneri et al. (2016) get a significant state dependence in the short run (the impact multiplier during expansions is approximately 1, as opposed to 2 during recessions), the difference disappears in the medium horizon.

In this paper, we propose an alternative explanation for the asymmetric effects of fiscal policy by developing a tractable model based on endogenously binding borrowing constraints. Building on Guerrieri and Iacoviello (2017), we incorporate collateral constraints that are tied to the value of housing wealth into a medium-scale dynamic stochastic general equilibrium (DSGE) model. In this framework, a share of households face borrowing constraints that are binding in normal times and recessions, but become 'slack' during expansions when their consumption is high. As a result, during recessions any additional income from fiscal expansion and associated loosening of their borrowing constraint is spent on consumption; however, during expansions the borrowing constraint is slack, and the marginal utility of consumption is lower, and additional income is smoothed across time, which results in lower output increases. Therefore fiscal policies that raise household income when the marginal propensity to consume is higher (when the borrowing constraint is binding) will have a larger impact than when this is not the case.

While the fact that models with credit-constrained consumers produce higher fiscal multipliers is well-understood, these agents are permanently constrained in much of the existing work, at odds with state-dependency of responses to fiscal policy (see, for example, Galí et al. 2007). A key advantage of our framework is the endogenous nature of the slackness in the credit constraint in our model, which allows us to establish the state dependence of multipliers. In order to examine the potential asymmetries in fiscal policy, we construct a medium-scale New Keynesian DSGE model with eight fiscal instruments. Our model economy is populated by two types of households: patient (lenders) and impatient (borrowers). Both households supply labour to firms and the government, consume the final good and accumulate housing; however, impatient households discount the future at a higher rate and, as a result, borrow from patient households that also lend to the government and accumulate physical capital. Central to our framework is the explicit treatment of housing wealth, which has a key role in determining the value of the collateral constraints for impatient agents, and therefore the implications of the fiscal shocks. The model features nominal rigidities in price and wage setting and real frictions of adjustment costs, monopolistic competition in the nonresidential good sector, capital utilization costs, and external habits in consumption.

We find that fiscal policy is indeed state-dependent, and fiscal effectiveness varies substantially across the cycle. Moreover, the rich fiscal structure that we employ in our framework allows us to calculate the state dependence of fiscal policy for a large number of fiscal instruments. For example, we find four-quarter cumulative spending multipliers to be, on average, $49 \%$ lower during consumption booms compared to when the borrowing constraint is always binding; tax multipliers are on average $33 \%$ lower in booms. We find clear heterogeneity across fiscal instruments; multipliers in targeted transfers vary the most between booms relative to normal and recessionary times, as these policies strongly impact on the consumption dynamics of impatient households. Our consideration of such an extensive set of fiscal instruments allows us to generalize 
our results and identify new outcomes such as in the case of capital taxes, where expansionary policy (a cut in taxes) leads to a substitution from labour to capital, and subsequently lower incomes for credit-constrained agents. Under this scenario, having more access to borrowing in the boom allows these households to mitigate the impact of the policy, increasing their consumption in addition to the expansionary effects from the policy of increasing the productive capacity of the economy. Our results further suggest that it is the credit conditions of agents that determine the asymmetry of fiscal multipliers, and not the fiscal action itself, as the size and direction of the latter play a limited role in the former. That is, only shocks to transfers and labour taxes can have a substantial effect on the access to credit for impatient agents, and therefore, for the majority of policies, the size and expansionary/contractionary nature of the fiscal action does not lead to asymmetries itself. The implication of this is that the impact of fiscal policy is determined by the underlying economic environment much more than by the size and the direction of fiscal action.

Moreover, the asymmetries in the effectiveness of fiscal policy persist in the long run, in contrast to the results of Canzoneri et al. (2016), who find the non-linearity of their state-dependent multipliers diminishing beyond ten quarters; this persistence better matches the empirical results that typically look at multipliers over the medium term (for example, Auerbach and Gorodnichenko (2012) measure output multipliers over five years). Furthermore, our modelling assumptions mean that higher fiscal multipliers are present in both normal times as well as downturns, making them the rule rather than the exception; this is consistent with the empirical estimates from Tagkalakis (2008) and Fazzari et al. (2015).

To provide evidence for the mechanism of occasionally binding collateral constraints, we estimate the model using the simulated method of moments to demonstrate that such constraints better match the skew in macroeconomic data; a model without occasionally borrowing constraints cannot replicate this skew. Further, we empirically estimate multipliers from exogenous tax changes identified in Romer and Romer (2010) using the smooth transitioning VAR (STVAR) process of Auerbach and Gorodnichenko (2013); our estimates suggest that multipliers are lower in booms in the housing market, in credit and in the general economy, providing further evidence for the central mechanism proposed in this paper.

An additional advantage of our framework with its rich set of policy instruments is that we can explore the state dependence of fiscal multipliers in nine separate cases: five government spending policies (government consumption, government investment, transfers, targeted transfers and public employment) and four tax instruments (employers' social security contributions and labour, consumption and capital taxes). Given that the existing two theoretical studies employ one type of fiscal multiplier eachpublic employment in Michaillat (2014) and government consumption in Canzoneri et al. (2016) - it is important to establish whether the state dependence of fiscal multipliers is limited to certain instruments or applies generally. Doing this also allows us to map our results to the estimated fiscal multipliers, which vary substantially across different types of public spending (see, for example, Auerbach and Gorodnichenko 2013). More importantly, our findings on the state-dependency of individual fiscal multipliers enable us to present policy prescriptions for disaggregated fiscal policy, with crucial implications for policy design, particularly in downturns.

The rest of the paper is organized as follows. Section I presents a detailed description of our model economy and the policy-making structure. Section II provides a number of fiscal experiments towards uncovering the state-dependent nature of fiscal policy 
effectiveness. Further extensions and robustness checks are presented in Section III. Section IV assesses the empirical relevance of our framework with occasionally binding constraints by using the simulated method of moments of the model and STVAR estimates, and discusses our results within the context of the existing empirical literature. Section V concludes.

\section{THE MODEL}

Our model builds upon that of Guerrieri and Iacoviello (2017) in two clear ways: first, we endogenize the production of the residential (durable) good; and second, we develop a full fiscal sector with eight policy instruments and nine policy experiments. ${ }^{2}$ In what follows, we present the key features of the model structure; the rest of the model description is presented in an Online Appendix.

\section{Households}

As in Iacoviello and Neri (2010), there is a continuum of measure 1 of households in each of the two groups: 'patient' and 'impatient'. Both types of household consume residential and non-residential goods, and supply labour to production. The key difference between the two types of household is that the patient discount the future at a lower rate than the impatient, and hence the former are lenders to the latter; the value of housing stock of the impatient agents acts as collateral against their borrowing, as in Iacoviello (2005).

Patient households The utility function for each patient household is given by

$$
E_{0} \sum_{t=0}^{\infty} \beta^{t} \varepsilon_{t}^{B}\left(\Gamma_{c}^{P} \ln \left(C_{t}^{P}(i)-h^{P} C_{t-1}^{P *}(i)\right)+\varepsilon_{t}^{H} \sigma_{h} \ln \left(H_{t}^{P}(i)\right)-\frac{1}{1+\sigma_{l}}\left(L_{t}^{P}(i)\right)^{1+\sigma_{l}}\right)
$$

where superscript $P$ is used for patient agents, $i$ indicates a particular household, and $t$ represents time; $\beta$ is a subjective discount factor; $\sigma_{l}$ is the inverse elasticity of labour $(L)$; $\sigma_{h}$ denotes a weight on housing in utility; $\varepsilon_{t}^{B}$ and $\varepsilon_{t}^{H}$ denote shocks to intertemporal preferences and housing preferences as in Iacoviello and Neri (2010); $C^{P}$ and $H^{P}$ represent consumption of the final good and housing, respectively; $h^{P}$ denotes the external habit parameter, $C^{P *}$ denotes average consumption of patient households, and $\Gamma_{c}^{P}$ is a scaling factor as in Iacoviello and Neri (2010). ${ }^{3}$ Each patient household receives income from the following sources: their after-tax labour income $\left(1-\tau_{t}^{l}\right)\left(w_{t}^{P}(i) L_{t}^{P}(i)\right)$, where $\tau_{t}^{l}$ and $w_{t}^{P}$ denote the labour tax and wage rate; the after-tax capital income $\left(1-\tau_{t}^{k}\right)\left[r_{n, k, t} u_{n, t}(i) \bar{K}_{n, t-1}(i)\right]$, where $\tau_{t}^{k}$ denotes the capital tax rate, and $\bar{K}_{n}, u_{n}$ and $r_{n, k}$ $(n \in\{c, h\}$ ) denote the physical stock of capital, the utilization and rental rate of capital used in the production of the consumption $(n=c)$ and the housing good $(n=h)$; the aftertax dividend income $\left(1-\tau_{t}^{k}\right) \operatorname{div}_{t}(i)$; interest income from holdings of government bonds $(B)$ and loans to the impatient agents (LO), $\left(\left(R_{t-1}-1\right) / \pi_{t}\right)\left(B_{t-1}(i)+\mathrm{LO}_{t-1}(i)\right)$, where $R_{t-1}$ is the gross nominal interest rate on one-period bonds and $\pi_{t}=P_{t} / P_{t-1}$ is gross inflation; and lump sum transfers from the government $\mu \mathrm{TR}_{t}$, where $\mu$ is the share of government transfers received by patient households.

Each patient household $i$ spends: $\left(1+\tau_{t}^{c}\right) C_{t}^{P}(i)$ on the final consumption good, where $\tau_{t}^{c}$ denotes the consumption tax rate; $\sum_{n=c, h} I_{n, t}(i)=I_{c, t}(i)+I_{h, t}(i)$ on investment in physical capital in the consumption and the housing producing sectors, respectively; 
$q_{t}\left[H_{t}^{P}(i)-\left(1-\delta_{h}\right) H_{t-1}^{P}(i)\right]$ on residential property, where $q_{t}=P_{h, t} / P_{t}$ denotes the relative price of housing and $\delta_{h}$ the depreciation of housing; $\operatorname{LO}_{t}(i)-\left(\mathrm{LO}_{t-1}(i) / \pi_{t}\right)$ and $B_{t}(i)-$ $\left(B_{t-1}(i) / \pi_{t}\right)$ on loans to impatient households and purchases of government bonds; and on costs arising from changes in the level of the capital utilization rate in both the consumption and housing sectors, $a\left(u_{n, t}\right) \bar{K}_{n, t-1}(i){ }^{4}$

Investment increases the stock of physical capital according to

$$
\bar{K}_{n, t}(i)=\left(1-\delta_{n, k}\right) \bar{K}_{n, t-1}(i)+\left[1-S\left(\frac{I_{n, t}(i)}{I_{n, t-1}(i)}\right)\right] \varepsilon_{t}^{I} I_{n, t}(i),
$$

where $\varepsilon_{t}^{I}$, as in Smets and Wouters (2007), denotes a shock to the price of investment relative to consumption goods.

The flow budget constraint of patient households can then be represented in real terms by

$$
\begin{aligned}
& \sum_{n=c, h} I_{n, t}(i)+\left(1+\tau_{t}^{c}\right) C_{t}^{P}(i)+q_{t}\left[H_{t}^{P}(i)-\left(1-\delta_{h}\right) H_{t-1}^{P}(i)\right]+\mathrm{LO}_{t}(i)+B_{t}(i) \\
& =\left(1-\tau_{t}^{l}\right)\left(w_{t}^{P}(i) L_{t}^{P}(i)\right)+\mu \mathrm{TR}_{t}+A_{t}^{P}(i)+\frac{R_{t-1}}{\pi_{t}}\left(B_{t-1}(i)+\mathrm{LO}_{t-1}(i)\right) \\
& \quad+\left(1-\tau_{t}^{k}\right)\left[\sum_{n=c, h} r_{n, k, t} u_{n, t}(i) \bar{K}_{n, t-1}(i)+\operatorname{div}_{t}(i)\right]-\sum_{n=c, h} a\left(u_{n, t}(i)\right) \bar{K}_{n, t-1}(i),
\end{aligned}
$$

where $A_{t}^{P}$ denotes state contingent securities, the presence of which implies that households are homogeneous with respect to consumption and assets choices; households are assumed to supply differentiated labour, and as such, without these securities would otherwise receive different income and have different expenditure allocations. ${ }^{5}$ Each patient household maximizes utility subject to the budget constraint, the capital accumulation equations and the demand for labour. Wages are set subject to Calvo (1983) frictions.

Impatient households The utility of impatient households evolves according to

$$
E_{0} \sum_{t=0}^{\infty} \gamma^{t} \varepsilon_{t}^{B}\left(\Gamma_{c}^{I} \ln \left(C_{t}^{I}(i)-h^{I} C_{t-1}^{I *}(i)\right)+\varepsilon_{t}^{H} \sigma_{h} \ln \left(H_{t}^{I}(i)\right)-\frac{1}{1+\sigma_{l}}\left(L_{t}^{I}(i)\right)^{1+\sigma_{l}}\right) .
$$

Each impatient household $i$ faces a flow budget constraint that states that the net labour income $\left(1-\tau_{t}^{l}\right)\left(w_{t}^{I}(i) L_{t}^{I}(i)\right)$ transfers $(1-\mu) \mathrm{TR}_{t}$, and the net acquisition of new loans $\mathrm{LO}_{t}(i)-\left(\mathrm{LO}_{t-1}(i) / \pi_{t}\right)$ should match total expenditure made up of: interest payments on outstanding loans $\left(\left(R_{t}-1\right) / \pi_{t}\right) \mathrm{LO}_{t-1}(i)$; the expenditure on consumption $\left(1+\tau_{t}^{c}\right) C_{t}^{I}(i)$; and the net acquisition of housing $q_{t}\left(H_{t}^{I}(i)-\left(1-\delta_{h}\right) H_{t-1}^{I}(i)\right)$. The impatient agents' budget constraint is therefore given by

$$
\begin{aligned}
& \frac{\left(R_{t-1}-1\right) \mathrm{LO}_{t-1}(i)}{\pi_{t}}+\left(1+\tau_{t}^{c}\right) C_{t}^{I}(i)+q_{t}\left(H_{t}^{I}(i)-\left(1-\delta_{h}\right) H_{t-1}^{I}(i)\right) \\
& =\mathrm{LO}_{t}(i)-\frac{\mathrm{LO}_{t-1}(i)}{\pi_{t}}+\left(1-\tau_{t}^{l}\right) w_{t}^{I}(i) L_{t}^{I}(i)+(1-\mu) \mathrm{TR}_{t}+A_{t}^{I}(i)
\end{aligned}
$$


The maximum that an impatient agent can borrow is defined by the constraint

$$
\mathrm{LO}_{t}(i) \leq(1-\tau) q_{t} H_{t}^{I}(i)
$$

where $\tau$ denotes the ratio of the down payment to the value of housing. This constraint states that the value of the loan must be less than or equal to the value of housing, adjusted by the down payment $(1-\tau) q_{t} H_{t}^{I}(i)$. Each impatient household maximizes utility subject to the budget constraint, the borrowing constraint and the demand for labour.

\section{Non-residential good sector}

Final good sector The final good $Y$ is produced by combining differentiated intermediate products using CES technology,

$$
Y_{t}=\left(\int_{0}^{1} Y_{t}(j)^{\left(v_{p}-1\right) / v_{p}} \mathrm{~d} j\right)^{v_{p} /\left(v_{p}-1\right)}
$$

where $v_{p} \geq 1$ denotes the elasticity of substitution among the differentiated outputs of intermediate firms, and $Y_{t}(j)$ denotes the output of the $j$ th producer. The retail firm chooses $Y_{t}(j)$ and maximizes profit of the form

$$
\operatorname{Prof}_{t}=P_{t} Y_{t}-\int_{0}^{1} P_{t}(j) Y_{t}(j) \mathrm{d} j
$$

where $P_{t}$ is the price of the composite good, and $P_{t}(j)$ denotes the price of the intermediate firm $j$. The first-order condition results in the demand equation for the output of intermediate producer $j, Y_{t}(j)=\left(P_{t} / P_{t}(j)\right)^{v_{p}} Y_{t}$, and the zero profit condition implies a price index

$$
P_{t}=\left(\int_{0}^{1} P_{t}(j)^{1-v_{p}} \mathrm{~d} j\right)^{1 /\left(1-v_{p}\right)} .
$$

Intermediate good sector The production technology of the monopolistically competitive intermediate good producers is given by the Cobb-Douglas function

$$
Y_{t}(j)=\varepsilon_{t}^{A, c} K_{c, t-1}^{\alpha}(j)\left[\left(N_{c, t}^{P}(j)\right)^{b_{1}}\left(N_{c, t}^{I}(j)\right)^{1-b_{1}}\right]^{1-\alpha} K_{g, t-1}^{\sigma_{g}}-\Phi
$$

where $\varepsilon_{t}^{A, c}$ denotes a productivity shock; $K_{c, t-1}(j)$ and $K_{g, t-1}$ denote public and private capital services, respectively; $N_{c, t}^{P}(j)$ and $N_{c, t}^{I}(j)$ denote labour supplied by the patient and impatient households, respectively; $\alpha$ denotes the share of capital in production; $b_{1}$ represents the share of patient households in total labour used in production; $\Phi$ is a fixed cost; and $\sigma_{g}$ denotes the elasticity of output with respect to public capital. Monopolistic producers choose $K_{c, t-1}(j), N_{c, t}^{P}(j)$ and $N_{c, t}^{I}(j)$ to minimize total real costs of production 
subject to the available technology, where all prices of inputs are taken as given. Monopolistic producers are also price setters, and prices are subject to Calvo (1983) frictions. In particular, in each period a share of firms $\theta_{p}$ are unable to re-optimize their price and change prices by the central bank's target rate of inflation.

\section{Residential good sector}

The competitive residential good producers use capital $K_{h}$ and labour of patient and impatient households, $N_{h}^{P}$ and $N_{h}^{I}$, to produce residential output HI using a CobbDouglas production function of the form

$$
\mathrm{HI}_{t}=\varepsilon_{t}^{A, h} K_{h, t-1}^{\alpha_{h}}\left[\left(N_{h, t}^{P}\right)^{b_{1}}\left(N_{h, t}^{I}\right)^{1-b_{1}}\right]^{1-\alpha_{h}} K_{g, t-1}^{\sigma_{g}},
$$

where $\varepsilon_{t}^{A, h}$ denotes a housing-sector-specific productivity shock, and $\alpha_{h}$ is the capital share in the production of housing. Producers of both the non-residential and residential goods are subject to employers' social security contributions $\left(\tau^{e r}\right)$, which adds a tax proportional to the total labour costs of the firm. Note that public capital $K_{g, t}$ enters the production function of both the intermediate goods producer (equation (8)) and the residential good producer (equation (9)) in the same way; in this respect, government capital is a public good as it is non-excludable and non-rivalrous.

\section{Monetary policy}

We adopt a standard formulation of monetary policy where policymakers follow a Taylor rule through which the nominal interest rate responds to movements in both output and inflation with some persistence $\rho$ :

$$
R_{t}=\max \left\{1, R\left(\frac{R_{t-1}}{R}\right)^{\rho}\left[\left(\frac{\left(\pi_{t}^{A}\right)^{0.25}}{\bar{\pi}}\right)^{\rho_{\pi}}\left(\frac{\mathrm{GDP}_{t}}{\mathrm{GDP}}\right)^{\rho_{y}}\right]^{1-\rho} \varepsilon_{t}^{R}\right\}
$$

where $\varepsilon_{t}^{R}$ is a monetary shock; GDP represents gross domestic product, which is given by

$$
\mathrm{GDP}_{t}=Y_{t}+q \mathrm{HI}_{t}+\left(1+\tau_{t}^{e r}\right)\left(w_{t}^{P} N_{g, t}^{P}+w_{t}^{I} N_{g, t}^{I}\right)
$$

where $N_{g, t}^{P}=\vartheta_{g} N_{t}^{P}$ and $N_{g, t}^{I}=\vartheta_{g} N_{t}^{I}$ represent public employment of patient and impatient agents, respectively; $\bar{\pi}$ is the central bank's target rate of inflation and $\pi_{t}^{A}=P_{t} / P_{t-4}$ is the annual inflation rate; $\rho_{\pi}$ and $\rho_{y}$ denote, respectively, the policymaker's aversion to deviations of inflation and output from their respective steadystate values. ${ }^{6}$ Variables with no time subscript represent steady-state values. As in Iacoviello and Neri (2010) equation (10) maintains that the nominal interest rate does not respond directly to variation in house prices.

\section{Fiscal policy}

The government budget constraint requires that spending on consumption $\left(G_{c}\right)$, investment $\left(I_{g}\right)$, transfers (TR) and public employment $\left(N_{g}^{P}\right.$ and $\left.N_{g}^{I}\right)$, as well as the 
repayment of previous period debt, is equal to tax receipts from the four revenue sources and issuance of new government debt. ${ }^{7}$ As such, the government budget constraint is given by

$$
\begin{aligned}
& \left(\frac{R_{t-1}}{\pi_{t}}\right) B_{t-1}+G_{t}+I_{g, t}+\mathrm{TR}_{t} \\
& =\tau_{t}^{c}\left(C_{t}^{P}+C_{t}^{I}\right)+\tau_{t}^{l}\left(w_{t}^{P} L_{t}^{P}+w_{t}^{I} L_{t}^{I}\right)+\tau_{t}^{e r}\left(w_{t}^{P} N_{t}^{P}+w_{t}^{I} N_{t}^{I}\right) \\
& \quad+\tau_{t}^{k}\left(r_{k, c, t} u_{c, t} \bar{K}_{c, t-1}+r_{k, h, t} u_{h, t} \bar{K}_{h, t-1}+\operatorname{div}_{t}\right)+B_{t},
\end{aligned}
$$

where $G_{t}=G_{c, t}+\left(1+\tau_{t}^{e r}\right)\left(w_{t}^{P} N_{g, t}^{P}+w_{t}^{I} N_{g, t}^{I}\right)$. For transfers, we adopt two scenarios: one where transfers are spread evenly across patient and impatient households $\left(\mu=b_{1}\right.$, where $b_{1}$ is the share of patient households in total labour used in production); and another where transfers are targeted to impatient agents who both have lower incomes and who respond more to changes in transfers $(\mu=0){ }^{8}$ In total, therefore, there are eight fiscal instruments and nine fiscal experiments at the disposal of the government (including both targeted and general transfers).

Public investment augments public capital according to

$$
K_{g, t}=\left(1-\delta_{k, g}\right) K_{g, t-1}+I_{g, t}
$$

where $\delta_{k, g}$ denotes the depreciation of public capital. Consistent with Ratto et al. (2009), Leeper et al. (2010b) and Traum and Yang (2015), we assume no adjustment costs or utilization rates for government capital; we test the sensitivity of our results to this in the first subsection of Section III. Fiscal policy rules are set similar to those used by Leeper et al. (2010a). We assume that fiscal policy responds countercyclically to the movements in debt, which implies that

$$
\frac{X_{t}}{X}=\left(\frac{B_{t}}{B}\right)^{\phi_{b, x}} \varepsilon_{t}^{x}, \quad \varepsilon_{t}^{x}=1+\eta_{x, t}+\eta_{x, t-1}+\eta_{x, t-2}+\eta_{x, t-3},
$$

where $x=\left\{\tau^{c}, \tau^{k}, \tau^{l}, \tau^{e r}, G_{c}, I_{g}, N_{g}^{P}, N_{g}^{I}, \mathrm{TR}\right\}$ is the set of fiscal instruments, and where $\eta_{x, t} \sim N\left(0, \sigma_{x}^{2}\right)$ are i.i.d. normally distributed errors. Shocks to fiscal instruments therefore last for only four quarters, with no persistence (as is adopted in Coenen et al. 2012); robustness to different specifications of these shocks is conducted in Appendix A.

\section{Equilibrium in residential and non-residential markets}

The homogeneous output of the residential good producer is purchased by patient and impatient households:

$$
\mathrm{HI}_{t}=H_{t}^{P}+H_{t}^{I}-\left(1-\delta_{h}\right)\left(H_{t-1}^{P}+H_{t-1}^{I}\right) .
$$

The final goods market is in equilibrium when the aggregate supply equals the aggregate public and private demand in the final consumption good, investment and housing. The resource constraint is given by 


$$
\begin{aligned}
& K_{c, t-1}^{\alpha}\left[\left(N_{c, t}^{P}\right)^{b_{1}}\left(N_{c, t}^{I}\right){ }^{\left(1-b_{1}\right)}\right]^{1-\alpha} K_{g, t-1}^{\sigma_{g}}-\Phi \\
& =s_{1, t}\left[I_{c, t}+I_{h, t}+C_{t}^{P}+C_{t}^{I}+G_{c, t}+I_{g, t}+a\left(u_{h, t}\right) \bar{K}_{h, t-1}+a\left(u_{c, t}\right) \bar{K}_{c, t-1}\right]
\end{aligned}
$$

where

$$
s_{1, t}=\left(1-\theta_{p}\right)\left(\tilde{p_{t}}\right)^{-v_{p}}+\theta_{p}\left(\frac{\bar{\pi}}{\pi_{t}}\right)^{-v_{p}} s_{1, t-1},
$$

where $s_{1, t}$ is a term denoting price dispersion.

\section{Are the EFFects of Fiscal Policy StATE-DePENDENT?}

\section{Time preference, borrowing constraints and consumption}

To explore the asymmetries in the model, a full understanding of the consumption decisions of impatient households is crucial given that it is through the impatient agents that the non-linear effects of policy are transmitted. The first-order conditions for impatient and patient households with respect to consumption are presented in the Euler equations

$$
\begin{aligned}
& \left(1-\lambda_{t}^{b}\right)\left(\frac{U_{c, t}^{I}}{P_{t}\left(1+\tau_{t}^{c}\right)}\right)=\gamma R_{t} E_{t} \frac{U_{c, t+1}^{I}}{P_{t+1}\left(1+\tau_{t+1}^{c}\right)}, \\
& \left(\frac{U_{c, t}^{P}}{P_{t}\left(1+\tau_{t}^{c}\right)}\right)=\beta R_{t} E_{t} \frac{U_{c, t+1}^{P}}{P_{t+1}\left(1+\tau_{t+1}^{c}\right)}
\end{aligned}
$$

where $\lambda^{b}$ is the price of borrowing (the ratio of Lagrange multipliers on the borrowing constraint and the budget constraint), and

$$
U_{c, t}^{m}=\Gamma_{c}^{m}\left[\frac{\varepsilon_{t}^{B}}{C_{t}^{m}-h^{m} C_{t-1}^{m}}-\frac{h^{m} \beta \varepsilon_{t+1}^{B}}{C_{t+1}^{m}-h^{m} C_{t}^{m}}\right]
$$

denotes the marginal utility of consumption for $m \in\{P, I\}$.

Using equation (17), it is straightforward to show that when $\lambda_{t}^{b}>0$, the following holds:

$$
\frac{U_{c, t}^{I}}{P_{t}\left(1+\tau_{t}^{c}\right)}-\gamma R_{t} E_{t} \frac{U_{c, t+1}^{I}}{P_{t+1}\left(1+\tau_{t+1}^{c}\right)}>0 .
$$

Put differently, when the constraint on borrowing is binding (when the first expression of inequality (19) is greater than the second), impatient agents would rather borrow more than they are permitted. This, in turn, is when the marginal utility of additional consumption $\left(U_{c, t}^{I} /\left(P_{t}\left(1+\tau_{t}^{c}\right)\right)\right)$ is greater than the expected cost of this borrowing $\left(\gamma R_{t} E_{t} U_{c, t+1}^{I} /\left(P_{t+1}\left(1+\tau_{t+1}^{c}\right)\right)\right)$ to the impatient agent. In this situation, any additional 
income in the current period (including any extra borrowings from the loosening of the borrowing constraint) is used for contemporaneous consumption. This suggests that when impatient consumption in the current period is sufficiently high, the constraint on their borrowing is no longer binding $\left(\lambda_{t}^{b}=0\right)$ and the two Euler equations of the patient and impatient households become similar. Intuitively, this is when the marginal utility of additional consumption from extra borrowing is equal to the expected cost of this borrowing. Put differently, when $\lambda_{t}^{b}=0$, impatient agents smooth any additional increase in income over the period in which they expect the borrowing constraint to be slack. In doing so, they reduce interest payments and this allows for a slightly higher consumption profile in the longer horizon. ${ }^{9}$

Iterating forward the Euler equations in equations (17) and (18) provides

$$
\begin{aligned}
U_{c, t}^{I} & =\prod_{l=0}^{i=\infty} E_{t}\left(\frac{\gamma}{1-\lambda_{t+l}^{b}} \frac{R_{t+l}}{\pi_{t+1+l}} \frac{1+\tau_{t+l}^{c}}{1+\tau_{t+1+l}^{c}}\right), \\
U_{c, t}^{P} & =\prod_{l=0}^{i=\infty} E_{t}\left(\beta \frac{R_{t+l}}{\pi_{t+1+l}} \frac{1+\tau_{t+l}^{c}}{1+\tau_{t+1+l}^{c}}\right),
\end{aligned}
$$

which confirms the intuition from above. When $\lambda_{t}^{b}=0$, the two equations become similar, where the difference in discount rates means that the impatient bring more consumption forward than the patient. In this situation, impatient households smooth any additional income over the horizon in which the borrowing constraint is slack $\left(\lambda_{t}^{b}=0\right)$, and their borrowing is lower than the constraint permits. The presence of $\lambda_{t}^{b}$ in equation (17) implies that any loosening of the borrowing constraint results in higher consumption today, whereas a tightening of the constraint has the reverse effect. ${ }^{10}$

\section{Policy experiments}

Provided that the constraint on borrowing for impatient agents is always binding $\left(\lambda^{b}>0\right)$, these agents borrow all that is permitted and there are no asymmetries in the dynamics from the model; that is, the impact of shocks in the model is symmetric. Therefore in order to identify non-linear effects of fiscal policy, this borrowing constraint needs to not bind for some time interval; this will happen when consumption today is so high that the marginal utility gained from further borrowing (and therefore further consumption) is equal to the marginal cost of borrowing, as stipulated by inequality (19). In this environment, shocks of the same magnitude will have different effects depending on how long the borrowing constraint on impatient households does not bind, or is 'slack'. In order to get the constraint to not bind, as in Guerrieri and Iacoviello (2017) we use a housing preference shock $\left(\varepsilon^{H}\right.$ in equations (1) and (4)) such that the stock and value of housing increases for impatient and patient agents, therefore increasing the borrowing potential of impatient households and thus consumption; we then increase the size of this shock in order to increase the number of periods in which the constraint does not bind. ${ }^{11}$

To calculate the size of fiscal multipliers, we include a small fiscal shock on top of the housing preference shock such that the length of the period in which the borrowing constraint does not bind is not altered; this fiscal shock is spread equally over four quarters before it subsequently dies (as specified in equations (13)). We then calculate 
multipliers by looking at the difference in variables with the additional fiscal shock compared to the counterfactual of including only the housing preference shock in the economy. In this respect, we find what Erceg and Lindé (2014) call a 'marginal' multiplier as the fiscal intervention is not of sufficient size to change the state of the economy. In the first subsection of Section III, we discuss results from extensions to these fiscal experiments, including where we allow for sizeable fiscal shocks such that policy can alter the time horizon over which the borrowing constraint on impatient households is not binding. The benchmark results from using the experiments as outlined above are consistent with these further extensions. Finally, note that the period when the borrowing constraint on impatient agents binds can be considered as the multiplier corresponding to both 'normal' and recessionary times, while when it does not bind the economy is experiencing good times or a 'boom'; the longer the constraint does not bind, the longer the boom.

In order to quantify the impact of policy on output, we employ the following metric to calculate cumulative fiscal multipliers $(M)$ :

$$
M_{T}=\frac{\sum_{j=0}^{T}\left(Y_{t+T}-Y_{0}\right)}{\sum_{j=0}^{T}\left(x_{t+T}-x_{0}\right)},
$$

where $T$ is the time horizon over which the multiplier is measured, $x$ is the respective fiscal instrument, and variables with a subscript zero are outcomes corresponding to the counterfactual of no fiscal change. When $x$ is a government spending instrument, we use the monetary value of the change in spending as the denominator. (Throughout the paper, we use the expression 'government spending' to represent the four spending instruments in the model in total.) To ensure consistency, for tax multipliers we use the change in tax revenues were all other variables (with the exception of the relevant tax rate) to remain the same. ${ }^{12}$ In solving the model, we apply the toolkit for solving dynamic models with occasionally binding constraints developed in Guerrieri and Iacoviello (2015).

\section{Calibration}

We calibrate the model using values adopted in the previous literature and data from the USA between 1985 and 2016, as outlined in Table 1. We set the ratio of government consumption, investment, transfers to output and the share of public employment to total employment to match the averages in the data for the period 1985-2016 (we take 1985 as the starting point to be consistent with Guerrieri and Iacoviello (2017)). ${ }^{13}$ The calibration is in line with Trabandt and Uhlig (2011), Drautzburg and Uhlig (2015) and Alpanda and Zubairy (2016), who calibrate government consumption to GDP to $18 \%$, $15.3 \%$ and $18 \%$, respectively, and again Drautzburg and Uhlig (2015), who calibrate government investment to GDP to $4 \% .{ }^{14}$ In setting the tax rates, we rely on the dataset and methods used in Trabandt and Uhlig (2011). For the purposes of this paper, we modify their work in two dimensions: first, we recalculate the tax rates so that our starting point is 1985 (their average tax rates are calculated for the period from 1995); and second, we include both labour income taxes and employers' social security contributions (whereas Trabandt and Uhlig (2011) combine both in one tax rate). ${ }^{15}$ 
TABLE 1

CALIBRATION

\begin{tabular}{|c|c|c|c|}
\hline Parameter & Description & Value & Data/Source \\
\hline \multicolumn{4}{|l|}{ Preferences } \\
\hline$\sigma_{h}$ & Utility share of housing & 0.093 & $*$ \\
\hline$\sigma_{l}$ & Inverse Frisch elasticity of labour & 1 & GI \\
\hline$h^{P}$ & Patient habit persistence & 0.40 & IN \\
\hline$h^{I}$ & Impatient habit persistence & 0.61 & IN \\
\hline$\beta$ & Patient discount factor & 0.995 & GI \\
\hline$\gamma$ & Impatient discount factor & 0.9922 & GI \\
\hline$b_{1}$ & Share of patient agents & 0.5013 & GI \\
\hline$\tau$ & Down payment ratio & 0.1 & GI \\
\hline$\rho_{B}$ & Persistence in housing shock & 0.9835 & GI \\
\hline \multicolumn{4}{|l|}{ Technology } \\
\hline$\alpha_{c}$ & Share of capital in non-residential production & 0.3 & IN \\
\hline$\alpha_{h}$ & Share of capital in residential production & 0.1 & IN \\
\hline$\delta_{k, c}$ & Depreciation of non-residential capital & 0.0145 & $*$ \\
\hline$\delta_{k, h}$ & Depreciation of residential capital & 0.03 & $*$ \\
\hline$\delta_{h}$ & Depreciation of housing & 0.0101 & $*$ \\
\hline$\delta_{k, g}$ & Depreciation of public capital & 0.0151 & $*$ \\
\hline$\sigma_{g}$ & Elasticity of output w.r.t. public capital & 0.02 & LWY \\
\hline$\phi_{k}$ & Investment adjustment cost parameters & 14.25 & IN \\
\hline$\kappa$ & Capital utilization adjustment parameter & 2.2258 & IN \\
\hline$\theta_{p}$ & Price stickiness & 0.9182 & GI \\
\hline$\theta_{w}$ & Wage stickiness & 0.9163 & GI \\
\hline$v_{p}$ & Steady-state price markup & 0.2 & GI \\
\hline$v_{w}$ & Steady-state wage markup & 0.2 & GI \\
\hline \multicolumn{4}{|l|}{ Monetary policy } \\
\hline$\rho$ & Monetary policy persistence & 0.5509 & GI \\
\hline$\rho_{\pi}$ & Inflation Taylor rule weight & 1.7196 & GI \\
\hline$\rho_{y}$ & Output Taylor rule weight & 0.0944 & GI \\
\hline $\bar{\pi}$ & Quarterly inflation target & 1.005 & GI \\
\hline \multicolumn{4}{|l|}{ Fiscal policy } \\
\hline$\phi_{b, x}$ & Response of fiscal instruments to debt & 0.2 & \\
\hline$\tau^{c, x}$ & Consumption tax rate & 0.05 & TU \\
\hline$\tau^{l}$ & Labour tax rate & 0.2 & TU \\
\hline$\tau^{k}$ & Capital tax rate & 0.36 & TU \\
\hline$\tau^{e r}$ & Employers' social security contributions rate & 0.07 & TU \\
\hline$G / G D P$ & Public consumption and employment to GDP & 0.149 & 0.149 \\
\hline$I G / \mathrm{GDP}$ & Public investment to GDP & 0.041 & 0.041 \\
\hline TR/GDP & Transfers to GDP & 0.114 & 0.114 \\
\hline$\vartheta_{g}=N_{g}^{I} / N^{I}=N_{g}^{P} / N^{P}$ & Share of public employment & 0.147 & 0.147 \\
\hline \multicolumn{4}{|c|}{ Other ratios matched } \\
\hline$\left(C_{P}+C_{I}\right) / \mathrm{GDP}$ & Consumption to GDP & 0.645 & 0.645 \\
\hline
\end{tabular}

For the majority of the remaining parameters, we follow the calibration in Guerrieri and Iacoviello (2017), as outlined in Table 1. The exception to this is that our capital utilization cost and investment adjustment cost are based on the estimated values in Iacoviello and Neri (2010). The elasticity of fiscal instruments to debt $\left(\phi_{b, x}\right)$ is set to 0.2 , which means that all instruments are used to ensure government solvency and respond 
TABLE 1

Continued

\begin{tabular}{llcr}
\hline Parameter & \multicolumn{1}{c}{ Description } & Value & Data/Source \\
\hline$\left(I_{h}+I_{c}\right) / \mathrm{GDP}$ & Non-residential investment to GDP & 0.123 & 0.123 \\
$q \mathrm{HI} / \mathrm{GDP}$ & Residential investment to GDP & 0.042 & 0.042 \\
$\left(K_{c}+K_{h}\right) /(4 \times \mathrm{GDP})$ & Business capital to GDP & 2.107 & 2.239 \\
$q\left(H_{I}+H_{P}\right) /(4 \times \mathrm{GDP})$ & Housing value to GDP & 1.038 & 1.033 \\
$K_{g} /(4 \times \mathrm{GDP})$ & Public capital to GDP & 0.679 & 0.678 \\
$K_{h} /\left(K_{c}+K_{h}\right)$ & Share of residential capital in total capital & 0.009 & 0.007 \\
\hline
\end{tabular}

Notes

The abbreviations 'GI', 'IN', 'LWY' and 'TU' refer to Guerrieri and Iacoviello (2017), Iacoviello and Neri (2010) Leeper et al. (2010b), and Trabandt and Uhlig (2011), respectively.

* represents a value implied by other calibrations to fix steady-state shares to empirical values.

slowly to bring debt to its steady state; debt as a result of fiscal shocks is halved after 34 quarters, and sensitivity to this parameter is tested in Appendix A. We set the elasticity of output with respect to public capital equal to 0.02 , which is in line with the range of estimates discussed in Leeper et al. (2010b). We set the depreciation rate of public capital to 0.015 to match the ratio of public capital to GDP in the data. The estimates of habit persistence in non-residential consumption for the patient and impatient agents are taken from Iacoviello and Neri (2010) for the period 1989-2006; they also estimate habit persistence in housing to be indiscernible from zero. We calibrate the weight of housing in the utility function and the depreciation of housing to match the ratio of housing wealth to GDP and of residential investment to GDP; this implies a utility weight of 0.093 and a depreciation rate of 0.0101 , values very close to the ones used in Iacoviello and Neri (2010). Since Guerrieri and Iacoviello (2017) do not use housing production, we use the share of physical capital in production from Iacoviello and Neri (2010). Given the shares of capital in production, the capital income tax rate and the patient households' discount rate, we set the depreciation of both residential and non-residential capital to match the investment and capital to GDP ratios in the data. The depreciation rate of non-residential capital is set at 0.0145 , similar to rates used in Drautzburg and Uhlig (2015) and Alpanda and Zubairy (2016), and the depreciation rate of residential capital (0.03) is in line with Iacoviello and Neri (2010).

To assess the reliability of our calibration, we compare four-quarter output multipliers from our benchmark model specification (where borrowing constraints are always binding) to those presented in Coenen et al. (2012). ${ }^{16}$ In general, our multipliers fit within the range of estimates from the different models utilized in Coenen et al. (2012). The one exception is for consumption taxes, where we get higher multipliers; this is driven by the fact that our benchmark calibration for habit formation in consumption (for which we used the estimated results from Iacoviello and Neri (2010)) is lower. As can be seen in the final subsection of Section III, calibrating higher levels of habit persistence in consumption brings our consumption tax multipliers in line with those presented in Coenen et al. (2012) and has a limited effect on the key findings in our analysis.

\section{Dynamics}

In order to explore the transmission mechanism through which fiscal policy impacts on impatient agents' consumption (and subsequently the broader economy), we present 
dynamics from two fiscal experiments involving a shock to transfers (Figure 1) and government consumption (Figure 2). In these plots, the period over which the borrowing constraint on impatient agents is slack varies between zero and 18 quarters. ${ }^{17} \mathrm{As}$ discussed in the second subsection of this section, we get this borrowing constraint to not bind by shocking housing preferences $\left(\varepsilon^{H}\right)$ and then consider the impact of policy by including a further shock to the relevant fiscal instrument.

An increase in transfers increases both the income for impatient households and the level of government debt. In normal times, when $\lambda^{b}>0$, impatient households convert increased incomes into increased consumption for the four quarters while the shock is active (this includes additional borrowing arising from an increase in the value of the borrowing constraint). This is because the marginal utility of additional consumption for these households is higher than the marginal cost of borrowing, as discussed in the first subsection of this section. Higher demand from impatient agents brings about higher output, and inflationary pressures lead to an increase in the real interest rate, which subsequently leads to a fall in consumption of patient households, as indicated in equation (21).

When the borrowing constraint on impatient agents is not binding, on the other hand, these agents smooth any additional income over the period in which they expect their borrowing constraint to be slack, where changes in consumption are also driven by habit persistence (thus explaining the hump in impatient consumption over this smoothing period). This is when the marginal utility of additional consumption for these households is equal to the marginal cost of this consumption, which implies a smaller increase in impatient households' consumption in the short run, and therefore a smaller
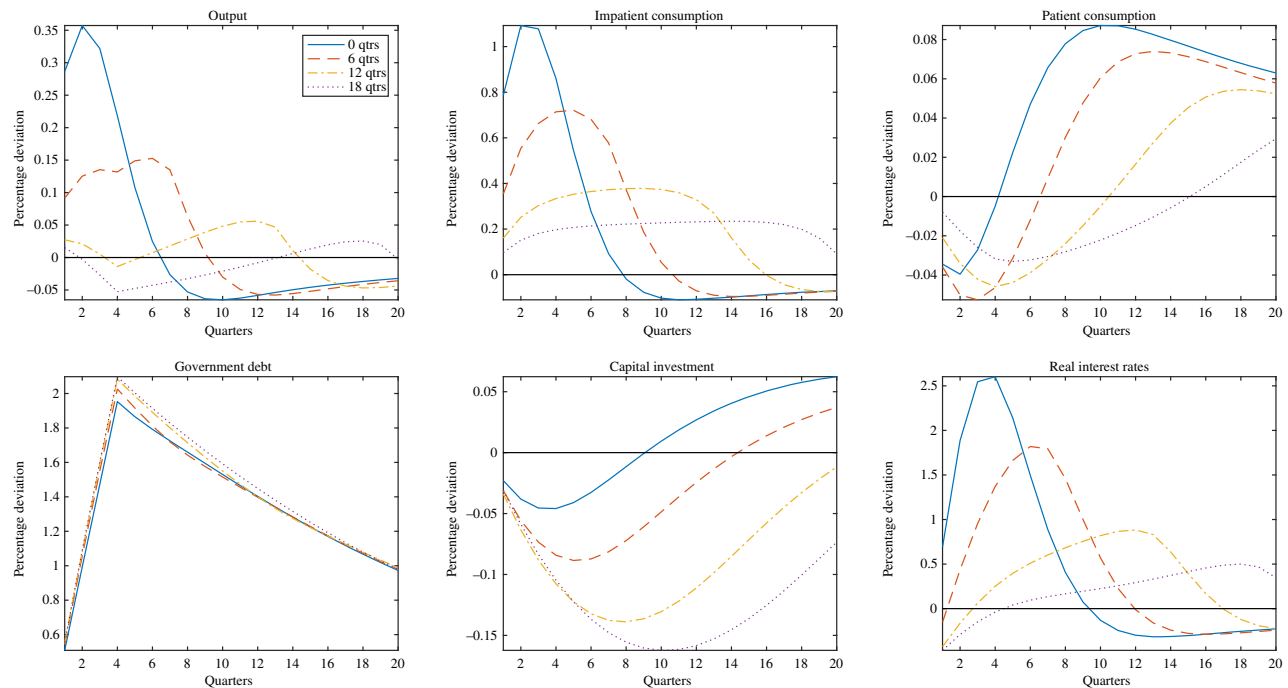

FIGURE 1. Dynamics from a transfer shock.

Notes: Dynamics from fiscal experiments where the borrowing constraint on impatient agents is slack for 0,6 , 12 and 18 quarters, as illustrated by the legend. In each instance, the results have been normalized to present the dynamics as a result of a shock to fiscal policy equal to $1 \%$ of output; dynamics for each variable are presented as percentage deviations from the steady state. The results present marginal impacts as the length of time for which the borrowing constraint is not binding is unaffected by the policy; the normalization is performed on shocks equal to 0.01 of this and is done for ease of presentation. [Colour figure can be viewed at wileyonlinelibrary.com] 

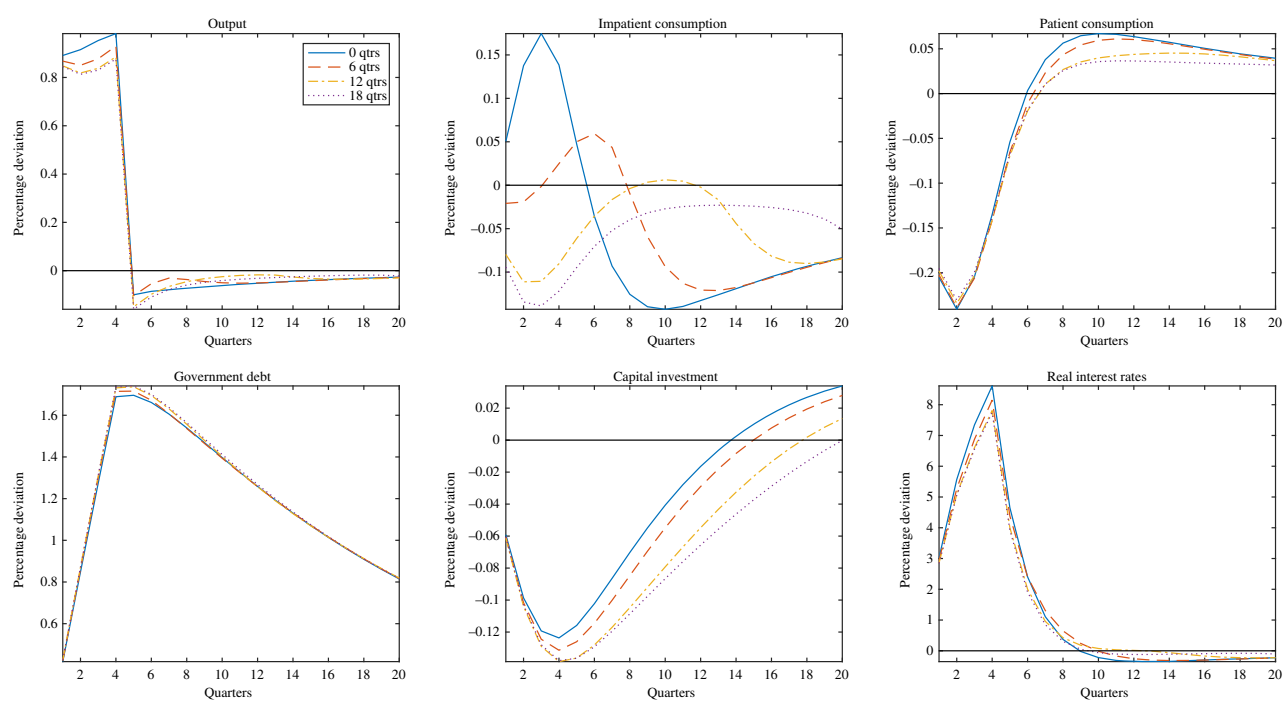

FIGURE 2. Dynamics from a government consumption shock.

Notes: See Figure 1. [Colour figure can be viewed at wileyonlinelibrary.com]

increase in output. This can be seen in the first and second panels of Figure 1 (for output and impatient agents' consumption, respectively) for differing periods over which the borrowing constraint is slack; a smoothing of impatient income leads to a smoothing of the effects of policy on output.

The smoothing actions of impatient households impact on the dynamics of patient agents in two ways. First, when the impatient borrowing constraint is not binding for a period of time, their smoothing of consumption leads to more persistent levels of inflation and subsequently higher real interest rates following the fiscal shock. Second, a smoothing of consumption by impatient agents leads to a smaller response to output arising from the fiscal action, and as such lower tax revenue and higher debt. The combination of anticipated higher interest rates and taxes (the latter needed to repay higher debt) leads patient agents to reduce expenditure more when impatient agents smooth their response to the policy, as is clear from equation (21). Therefore the response of output to fiscal stimulus in the short run is determined by the actions of impatient agents, which are influenced by whether they are constrained in their borrowing; over the medium term, however, the dynamics of output are determined by the actions of patient agents responding to the wealth outcomes of the policy.

Figure 2 presents dynamics arising from a government spending shock, for differing horizons over which the constraint on impatient borrowing is not binding; as is illustrated in the first panel, output multipliers tend to be lower than 1, suggesting a net crowding out of private expenditure to the policy. Similar to above, an increase in government consumption leads to increases in both impatient incomes and government debt. Higher output and inflation result in an increase in the real interest rate, which crowds out expenditure of patient households on impact, as indicated in equation (21). In normal and recessionary times, when $\lambda^{b}>0$, impatient agents increase their consumption in the short run when government consumption is increased, as extra aggregate demand increases labour demand and subsequently income for these agents. When the borrowing constraint on the impatient is not binding, on the other hand, these agents smooth the 
additional expenditure over the period in which they expect the borrowing constraint to be slack. Therefore the mechanism determining the consumption path of impatient households is the same as in the case of transfers. The main difference between the two policy experiments, however, is the fact that transfers impact directly the income of impatient households, whereas government consumption's impact is indirect through higher labour income. Therefore the increase in income and consumption is smaller in the case of government consumption (as shown in Figure 2), and the output effects of this policy come from public (and not private) demand. As the income being smoothed is smaller, the impact on the real economy resulting from this smoothing process is also smaller, and therefore the difference in response of output between expansions and recessions is not as large as in the case of transfers. Given this, the subsequent influence of consumption smoothing of impatient agents on patient households' expenditure via the channels discussed above (expected real interest rates and taxes) is also smaller, as can be seen in Figure 2.

\section{Fiscal multipliers}

To extend the analysis to all nine fiscal experiments, the first column of Figure 3 presents four-quarter cumulative output multipliers (vertical axis) for differing periods for which the constraint on impatient households' borrowing does not bind (horizontal axis); note that the plots present step functions as dynamics will be altered with only discrete changes in the time horizon over which this borrowing constraint is not binding. The intuition from above - that the longer the slack in the borrowing constraint, the smaller the fiscal policy effect on output-is maintained. ${ }^{18}$ As discussed above, in periods of slack, impatient agents are already consuming enough to not use their full credit capacity, and increases in their incomes during these periods lead to a lower consumption response of impatient agents compared to when their borrowing constraint binds. For example, average government spending multipliers are $49 \%$ lower when there is slack in the impatient borrowing constraint for 20 quarters compared to when this is always binding; similarly, taxation multipliers are lower by (on average) $33 \%$ between the two benchmarks. The largest non-linearities in multipliers are for targeted and general transfers and labour taxes, which are $0.61,0.28$ and -0.29 , respectively, in normal and recessionary times when the borrowing constraint binds, and approximately zero when there is slack for 20 quarters.

The one exception to the main result is for capital taxes that have a higher impact on the economy when the impatient borrowing constraint is not binding. In normal and recessionary times $\left(\lambda^{b}>0\right)$, a cut in capital taxes leads to a substitution from labour to capital, lowering labour income and therefore impatient consumption. In this situation, impatient households would prefer to borrow more ( $\lambda^{b}$ increases), which they can do if the borrowing constraint is not binding. Therefore a decrease in capital taxes has a smaller negative effect on the consumption of impatient households during expansion, and as a result, there is an additional improvement in output resulting in a higher multiplier. The distortionary nature of taxes can lead to the general intuition to break, but only in our model for taxes on capital; for all other instruments, expansionary policy leads to higher incomes for impatient agents and as such, if their borrowing constraint is not binding at the time of the policy, then output multipliers are lower.

The degree to which the effects of fiscal policy are non-linear is determined by the degree to which the effectiveness of policy is influenced by the consumption movements of impatient agents. If these movements are small when the borrowing constraint binds 

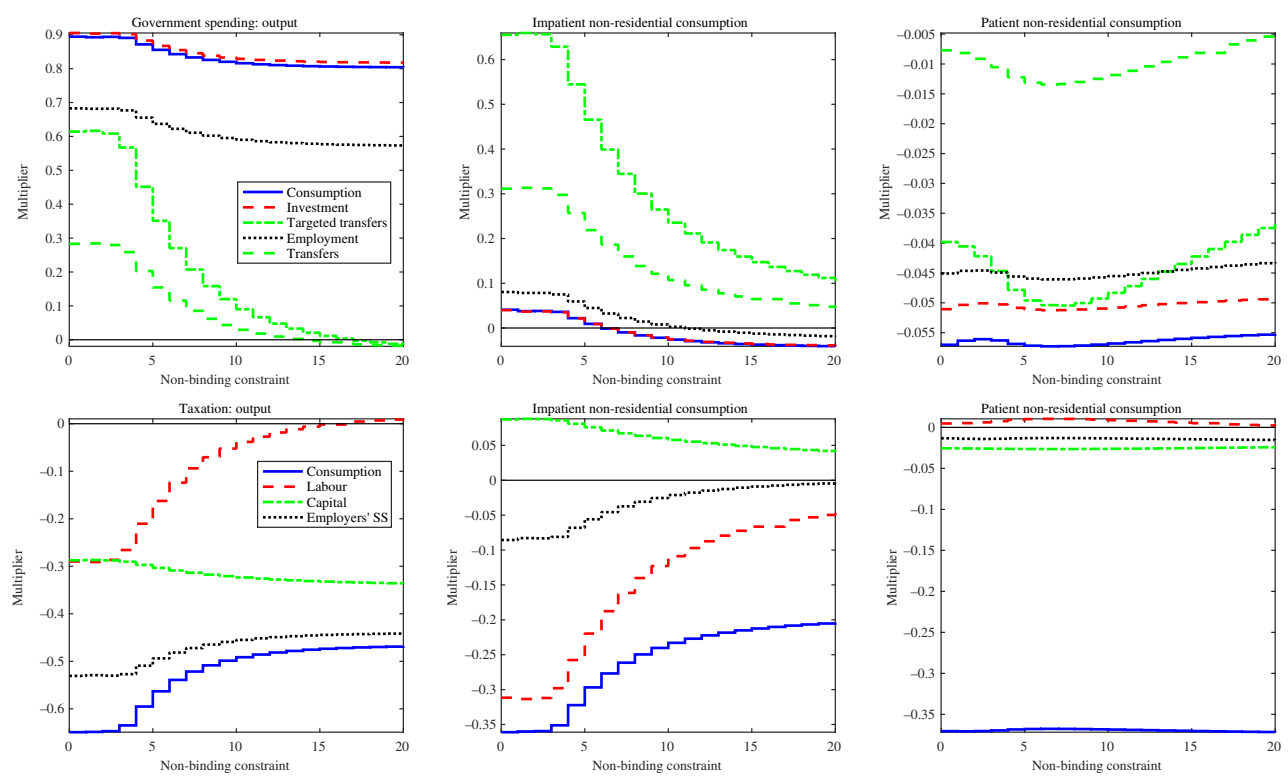

FIGURE 3. Four-quarter cumulative multipliers.

Notes: Cumulative multipliers for the nine fiscal experiments for differing horizons over which the borrowing constraint on impatient households does not bind; the first column presents output multipliers, the second column presents impatient non-residential consumption multipliers, and the final column presents patient non-residential consumption multipliers. The first row presents results for government spending instruments, and the second row presents taxation instruments. [Colour figure can be viewed at wileyonlinelibrary.com]

(for example, when the government increases spending on consumption, investment and employment, or when it decreases employers' social security contributions or taxes on capital), then the non-linearity of the response to fiscal policy is smaller. Cumulative four-quarter consumption multipliers presented in the second and third columns of Figure 3 demonstrate that impatient consumption multipliers are largest when their borrowing constraint is binding for targeted and general government transfers, and labour and consumption taxes. As such, these instruments lead to the most non-linear of outcomes in both impatient consumption and output; note that the consumption of patient agents is largely unaffected by the actions of the impatient in the four-quarter horizon. Patient agents have higher discount factors, and their consumption is influenced by the path of expected future real interest rates and consumption taxes (as demonstrated in equation (21)); although the actions of the impatient influence these, the effects come over the medium term, and as a result, four-quarter consumption multipliers are not as volatile as for impatient households.

To examine further the role of binding versus non-binding borrowing constraints on fiscal outcomes, Figure 4 presents a decomposition of four-quarter cumulative output multipliers for each of the nine fiscal experiments, separated between government spending and tax instruments. The movement of each component of GDP is examined to determine what is contributing to the movement in total output over the first four quarters of the fiscal intervention; for each fiscal experiment, two results are presented side-by-side, one where the borrowing constraint on impatient agents is always binding (left-hand bar), and another where it is slack for 20 quarters (right-hand bar). These results illustrate that the movements in impatient agents' consumption are the biggest 

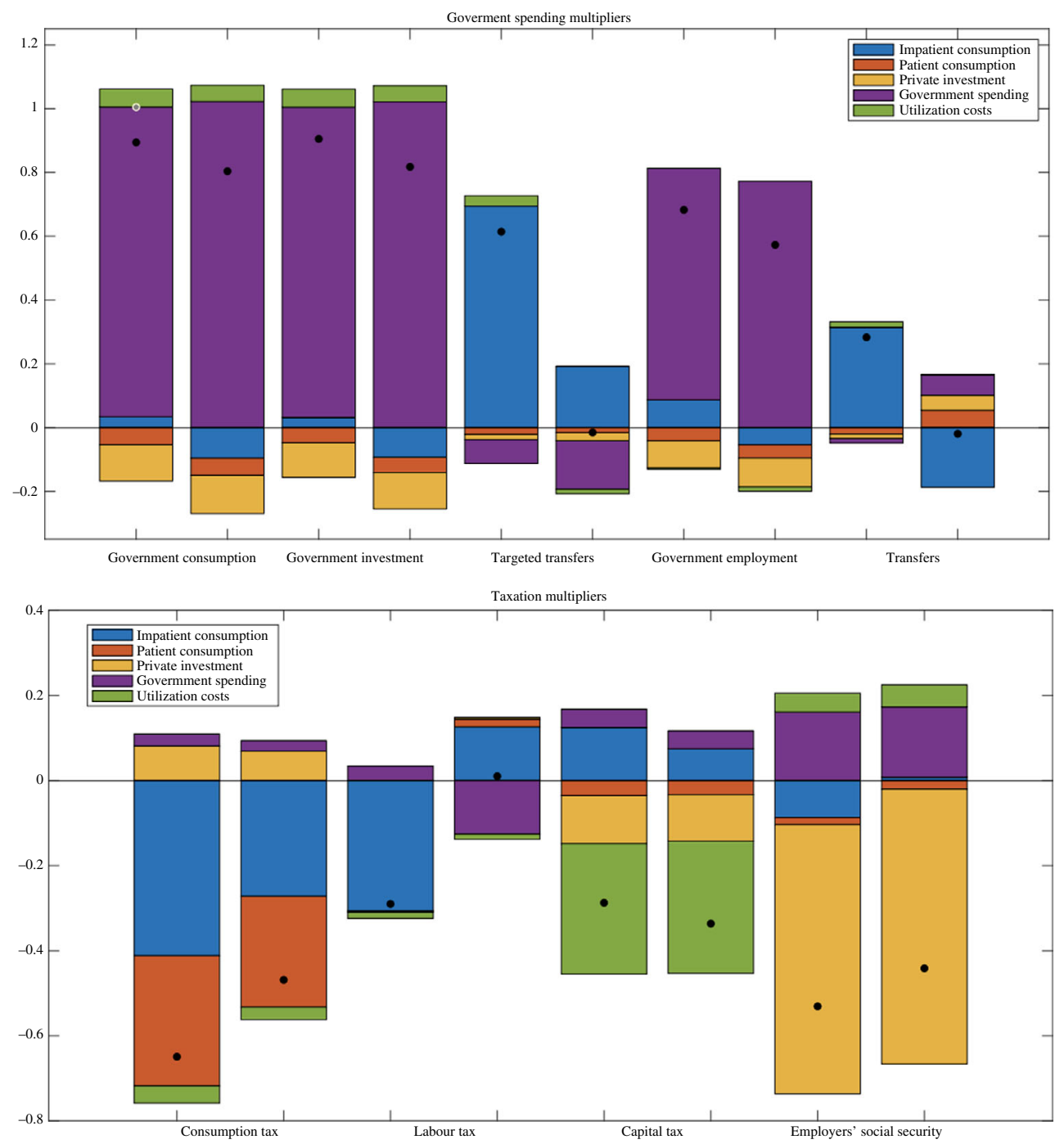

FIGURE 4. Decomposing four-quarter cumulative output multipliers.

Notes: A decomposition of output multipliers for each instrument (along the horizontal axis) where each instrument has two bars, representing a pair of values: in the left-hand bar, the borrowing constraint on impatient agents is always binding; in the right-hand bar, it is slack for 20 quarters. The decompositions separate between the elements that contribute negatively and positively to the four-quarter cumulative output multiplier, with the circle-point in each bar representing the value of the multiplier (the net of the positive and negative effects). [Colour figure can be viewed at wileyonlinelibrary.com]

source of non-linearity in these multipliers; the bars that represent impatient spending are those that vary the most between the different scenarios. It follows, therefore, that when impatient spending is not a large contributor to the output multiplier, the difference in results relative to when the borrowing constraint is not binding is smaller; that is, for those policies that do not require movements in impatient households' consumption to change output, fiscal effects are less non-linear. 
As highlighted in Figures 1 and 2, although the smoothing actions of impatient agents reduce the output response of policy in the short term, when their borrowing constraint is slack, over a longer period it improves output as consumption is spread over the longer horizon. This smoothing of actions by the impatient agents leads to less nonlinearity in multipliers when measured over a long horizon; this is confirmed in the first column of Figure 5, which plots 20-quarter cumulative output multipliers. Non-linearity is still observed, and although the percentage changes in output multipliers are similar, the absolute range of these values is smaller. Targeted and general transfers continue to be the most non-linear spending instruments, and 20-quarter cumulative multipliers are negative for general transfers when there is slack in the impatient borrowing constraint. These negative multipliers result from the rise in distortionary taxes to pay for the expansionary policy, and from the behaviour of patient households, as discussed in the previous subsection.

Over short time horizons, the non-linear response of fiscal multipliers is determined by the consumption of impatient agents; however, evaluating a period that nests the entire time in which borrowing constraints are slack (and therefore the period over which impatient consumption is smoothed), it is the response of patient agents that becomes more important. This can be seen in the second and third columns of Figure 5, which presents 20-quarter cumulative consumption multipliers for the two types of household for differing periods over which credit constraints are slack. Whereas in Figure 3 the nonlinearity in four-quarter cumulative consumption multipliers is driven by impatient agents, when the whole period over which these agents can smooth their consumption is considered (as in Figure 5), the non-linearity is driven by patient households.

As discussed above, the difference in the four-quarter output multipliers between expansions and recessions stems from the consumption smoothing of impatient households during expansions. Over the 20-quarter period, the entire smoothing exercise is completed, therefore there is limited volatility in the impatient households'
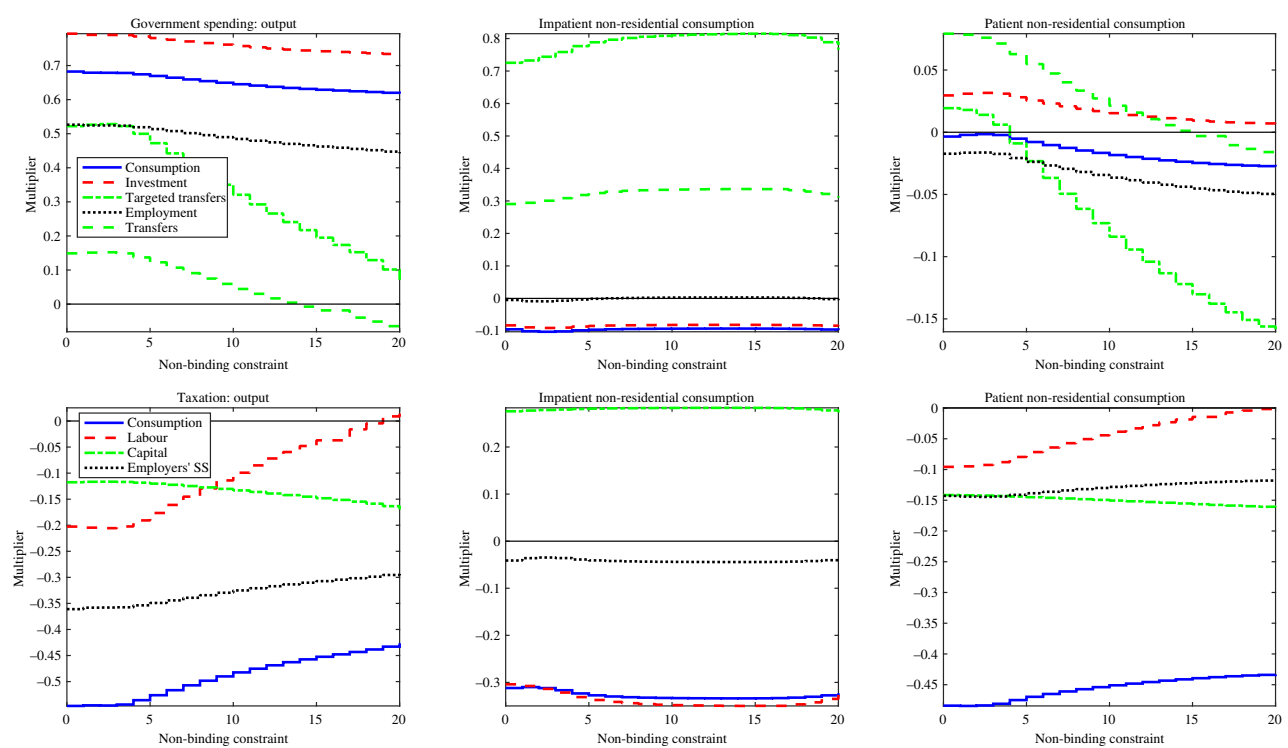

FIGURE 5. Twenty-quarter cumulative multipliers.

Notes: See Figure 3. [Colour figure can be viewed at wileyonlinelibrary.com] 
consumption multiplier. On the other hand, the smoothing process of impatient households results in more persistent real interest rates and larger increases in the present discounted value of taxes, which leads to greater crowding out of patients' consumption and therefore a lower consumption multiplier for these households. There is therefore both a short-run and a long-run non-linearity to fiscal policy. In this respect, our results differ from those presented in Canzoneri et al. (2016), which uses costly financial intermediation to produce asymmetric fiscal multipliers; in their paper, although the short-run multipliers are different in recessions and expansions, there is limited nonlinearity over a longer time horizon (beyond ten quarters).

\section{FURTHER EXTENSIONS}

\section{Further fiscal experiments}

As discussed in the second subsection of Section II, the fiscal experiments in our benchmark specification featured small temporary shocks spread over four quarters. To examine the non-linear effects of policy further, we now consider larger shocks that can generate substantial changes in macroeconomic outcomes. In this respect, these shocks can influence the time horizon over which the borrowing constraint on impatient households is not binding, and therefore we now present average multipliers compared with the 'marginal' effects analysed above.

We apply housing preference shocks of different values to change the underlying conditions of the economy; column (1) of Table 2 presents the percentage change in output in the first quarter as a result of the different values for these shocks, conditional on there being no fiscal intervention and borrowing constraints always binding. We then allow a fiscal expansion of $1 \%$ of quarterly GDP over four quarters (therefore a stimulus of $0.25 \%$ of annual GDP per quarter), and record the average multipliers as a result of this intervention across the nine fiscal instruments; these multipliers are presented in the remaining columns of Table 2 .

Now consider the results of targeted transfers (column (4) of Table 2). When output is higher than in steady-state, targeted transfers have a lower multiplier compared to when the economy is in a recession. This result follows from the intuition presented above; when output and incomes are high, house prices are elevated and the borrowing constraint on impatient agents does not bind, leading to lower marginal propensities to consume for these agents and lower fiscal multipliers. The bigger the boom in the economy, the longer the horizon over which the borrowing constraint will be slack. When output is below that of steady state, incomes are lower, and therefore impatient agents have a higher marginal propensity to consume, thus leading to higher multipliers as a result of any fiscal intervention. Four-quarter cumulative multipliers for targeted transfers range from near zero in a boom, to 0.7 in recessions. Two components influence this variability: the underlying economy, which influences the borrowing conditions of impatient agents; and the impact of the fiscal policy itself, further changing the horizon over which borrowing constraints are slack.

Note that the variability in fiscal multipliers in Table 2 in the other instruments is lower, especially when the economy is at the steady-state levels of output or below. When this is true, the borrowing constraint on impatient households always binds, and therefore the only change in multipliers comes from the fiscal intervention itself influencing impatient agents' borrowing conditions, giving some slack in their constraint. The fiscal instruments that have a smaller impact on impatient incomes and house prices 
TABLE 2

Four-Quarter Cumulative Average Fiscal Multipliers

\begin{tabular}{lccccccccc}
\hline$(1)$ & $(2)$ & $(3)$ & $(4)$ & $(5)$ & $(6)$ & \multicolumn{1}{c}{$(7)$} & \multicolumn{1}{c}{$(8)$} & \multicolumn{1}{c}{$(9)$} & \multicolumn{1}{c}{$(10)$} \\
$\% \Delta \mathrm{GDP}_{t}$ & $G$ & $I^{G}$ & \multicolumn{1}{c}{$\mathrm{TR}^{\prime}$} & \multicolumn{1}{c}{$N_{g}$} & \multicolumn{1}{c}{$\mathrm{TR}$} & \multicolumn{1}{c}{$\tau^{c}$} & \multicolumn{1}{c}{$\tau^{l}$} & $\tau^{k}$ & $\tau^{e r}$ \\
\hline 4 & 0.805 & 0.819 & 0.003 & 0.576 & -0.013 & -0.472 & 0.004 & -0.333 & -0.443 \\
3 & 0.808 & 0.821 & 0.020 & 0.579 & -0.004 & -0.476 & -0.005 & -0.330 & -0.446 \\
2 & 0.813 & 0.826 & 0.052 & 0.586 & 0.012 & -0.485 & -0.021 & -0.324 & -0.452 \\
1 & 0.830 & 0.842 & 0.119 & 0.605 & 0.053 & -0.511 & -0.062 & -0.311 & -0.469 \\
0 & 0.889 & 0.900 & 0.315 & 0.670 & 0.199 & -0.617 & -0.207 & -0.287 & -0.527 \\
-1 & 0.894 & 0.905 & 0.486 & 0.683 & 0.272 & -0.648 & -0.279 & -0.287 & -0.531 \\
-2 & 0.894 & 0.905 & 0.552 & 0.683 & 0.283 & -0.649 & -0.290 & -0.287 & -0.531 \\
-3 & 0.894 & 0.905 & 0.580 & 0.683 & 0.283 & -0.649 & -0.290 & -0.287 & -0.531 \\
-4 & 0.894 & 0.905 & 0.604 & 0.683 & 0.283 & -0.649 & -0.290 & -0.287 & -0.531 \\
\hline
\end{tabular}

Notes

Average four-quarter multipliers where house price shocks of different sizes are used to change output by the percentages presented in column (1). The economy is then subsequently subjected to a fiscal expansion of one percentage point of annual GDP spread over four quarters.

will therefore demonstrate lower levels of volatility in Table 2; indeed, the variability of multipliers in Table 2 is correlated with that in Figure 3. Therefore it can be concluded that even though fiscal multipliers are state-dependent, the policy itself has a limited impact on its own effectiveness. The implication of this is that it is the underlying economic climate - in our model, the credit conditions - that determines the impact of fiscal intervention, not the direction of the fiscal action. We also consider other specifications for fiscal shocks, and other shocks to get the borrowing constraint on impatient households to occasionally not bind; qualitatively, the results are in line with those above, and details can be found in Appendix A.

\section{Monetary policy}

In order to put the results on the non-linearity of fiscal policy into context, in this subsection we extend our analysis in two dimensions: first, we consider another source of non-linearity, that of monetary policy being at its 'zero lower bound' (ZLB); and second, similar to the framework above, we consider whether the impact of monetary policy shocks on the general economy is non-linear by varying the time over which the borrowing constraint on impatient agents is slack. In order to consider the former, we use a preference shock to get the nominal interest rate to be at its ZLB for up to five quarters and then apply the small fiscal shocks from above to get multiplier values, as in the final subsection of Section II. To investigate potential non-linearities in monetary policy, we use a framework similar to that above, but now instead of applying a small fiscal shock for when the impatient borrowing constraint is slack for up to 20 quarters, we apply a small one-quarter monetary policy shock, reducing nominal interest rates. The results are normalized to show a percentage change in output over a four-quarter horizon to a onequarter change in the interest rate of 100 basis points. Results from these extensions are presented in Figure 6.

The first panel of Figure 6 demonstrates that fiscal policy multipliers are more nonlinear with changes in the ZLB length than with the borrowing conditions of impatient households: for example, government spending (tax) multipliers are 54\% (38\%) larger 

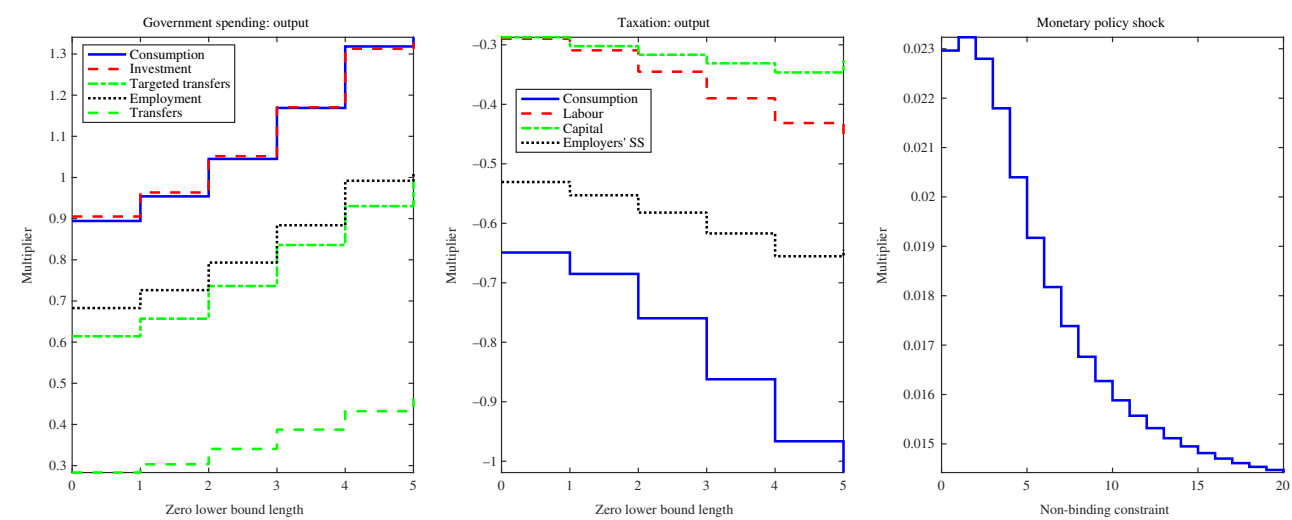

FIGURE 6. Monetary policy extensions.

Notes: The first two panels present fiscal multipliers for spending and tax instruments, respectively, for periods over which the ZLB is binding for between zero and five quarters. The third panel presents results from a one-quarter monetary policy shock where the change in the interest rate lasts for one quarter and is equal to 100 basis points. [Colour figure can be viewed at wileyonlinelibrary.com]

than normal times with a ZLB length of five quarters. This is intuitive given that the nonlinearity in the results presented in the final subsection of Section II derive from the actions of impatient households (which account for half the economy in our benchmark calibration), whereas the ZLB has an impact on the whole economy. Fiscal expansions can have an inflationary effect that, when combined with the ZLB, lowers real interest rates, encouraging spending by both impatient and patient households. A period where the monetary ZLB is binding is likely to also be one where the borrowing constraint on impatient households is also binding, as it is unlikely that the former would occur in a consumption boom. As such, the coexistence of the ZLB and a recession would yield even greater state dependence and hence greater asymmetries in fiscal multipliers than those presented above. That is, the ZLB provides one end of the spectrum, where fiscal multipliers are high and the impatient borrowing constraint is always binding; whereas the other end of the spectrum is where the borrowing constraint on the impatient is expected to be slack for a long time horizon. The third panel of Figure 6 confirms that monetary policy shocks also have asymmetric impacts with smaller multipliers during consumption booms. We also consider other specifications and calibrations for the Taylor rule; qualitatively, the results are in line with those above, and details can be found in Appendix A.

\section{Further sensitivity}

In addition to the above, we also performed sensitivity tests for other parameter values, including (but not limited to): price and wage stickiness; the proportion of impatient households in the economy; the exclusion of employers' social security contributions, public employment and productive public capital in the model; and higher levels of habit persistence. Despite quantitative shifts in the sizes of multipliers, the non-linearity of fiscal impacts remains similar to that presented above; the results are robust to further sensitivity tests. We further present results in Appendix A from changes in other assumptions: allowing for a fixed housing stock (as in Guerrieri and Iacoviello 2017); including capital income tax on interest from government debt and loans; and 
incorporating an adjustment cost to public investment similar to that of private investment. The changes in these assumptions lead to changes in the underlying size of multiplier but have a limited effect on the variability of the effects of fiscal multipliers.

\section{EMPIRICAL EVIDENCE AND DISCUSSION}

Having explored the results from our theoretical model above, we now present a discussion of these findings in the context of the broader empirical literature. In what follows, we first provide support for the key mechanism driving our asymmetric multipliers (calling on existing literature, estimates from the theoretical model, and empirical multiplier estimates) before subsequently framing our findings in the context of existing empirical findings.

\section{Occasionally binding borrowing constraints}

The asymmetries in fiscal multipliers in our model derive from variation in the marginal propensity to consume (MPC) of impatient agents depending on the nature of their credit constraints. Bunn et al. (2018) demonstrate that the MPC of UK households is higher in the face of negative income shocks than that for positive ones. Importantly, Bunn et al. (2018) demonstrate that this variation can be explained by balance sheet characteristics concerning debt, liquidity and credit market access; it is concluded that a model with occasionally binding borrowing constraints replicates these results. Bunn et al. (2018) estimate that MPC values for those with mortgages (similar to the 'impatient' in our model) are higher than those in owner-occupied properties (similar to the 'patient' in our model), especially in the case of negative income shocks, where it is more likely for borrowing constraints to be binding. ${ }^{19}$ Christelis et al. (2019) find similar results using survey responses from Dutch households to demonstrate that the MPC of households is bigger out of negative income shocks compared to positive ones. Again, Christelis et al. (2019) demonstrate that this behaviour can be explained with a model incorporating occasionally binding credit constraints.

Iacoviello (2005) develops a model with collateral constraints tied to housing wealth to provide better estimates of the response of aggregate demand to house price shocks. Iacoviello and Neri (2010) further develop this model to allow the housing stock to be produced in its own sector, and demonstrate that spillover effects from this sector to the macroeconomy between 1965 and 2006 are non-negligible. Guerrieri and Iacoviello (2017) extend these models to allow collateral constraints to be occasionally binding, introducing an asymmetry in the response of consumption to shocks, which better explains the US economy during the great moderation and the Great Recession.

\section{Macroeconomic skew and the simulated method of moments estimation}

Models with asymmetries are better able to explain skewness in macroeconomic observations. For example, Jensen et al. (2020) document a negative skewness in business cycles and find that this skewness has been increasing over time in the USA. Jensen et al. (2020) then estimate a model with occasionally binding borrowing constraints on both households and firms to show that such a model can explain these dynamics when combined with the observation that leverage has been increasing over time. ${ }^{20}$ The intuition is that agents respond differently to positive shocks than to negative shocks (as outlined above), and when leverage is higher, the response to adverse outcomes is amplified as debt reduction becomes more burdensome. Abbritti and Fahr 
(2013) use downward nominal wage rigidity in an otherwise standard New Keynesian model to explain positive skewness in the growth rates of wages and unemployment, and negative skewness in output.

Panel A of Table 3 presents skewness statistics for real output, real consumption, real investment (in both the residential and non-residential sectors, and in the consumption of housing) and house prices for Hodrick-Prescott (HP) filtered data and quarter-on-quarter growth rates. The one variable for which there is clear evidence of a negative skewness is house prices; this results from many periods of low growth in prices, with short, sharp episodes of relatively higher falls in prices. Intuitively, this could be replicated with our model using occasionally binding borrowing constraints, as conditions are different for when house prices are rising compared to when they are falling.

To formally test whether our model with occasionally binding constraints can better explain these asymmetries in the data, we use the simulated method of moments (SMM) to estimate the size and persistence of non-fiscal shocks in the model $\left(\varepsilon^{B}, \varepsilon^{H}, \varepsilon^{I}, \varepsilon^{A, c}, \varepsilon^{A, h}\right)$ by minimizing the difference between standard deviations and the skewness of the four variables in Table 3, between the data and that resulting from the model with the estimated shock parameters. ${ }^{21}$ That is, we estimate shock parameters that best match the data for these moments. ${ }^{22}$ We perform this estimation twice for two versions of the model, one where borrowing constraints are occasionally binding (as in our model above) and one where they are always binding. By comparing the abilities of the two models to match the data, we assess the importance of allowing for occasionally binding borrowing constraints in the model, the mechanism that drives the results in our paper. The results are presented in Table 3.

TABLE 3

MODEl ESTIMATION AND EMPIRICAL SKEWNESS

\begin{tabular}{|c|c|c|c|c|c|c|c|c|}
\hline & \multicolumn{2}{|c|}{ A. Skew in data } & \multicolumn{3}{|c|}{ B. Standard deviation } & \multicolumn{3}{|c|}{ C. Skewness } \\
\hline & HP filter & Growth & Data & Occas. & Always & Data & Occas. & $\overline{\text { Always }}$ \\
\hline \multicolumn{9}{|c|}{ Estimation on occasionally binding constraint } \\
\hline Output & 0.135 & $-1.184 *$ & 1.037 & 1.037 & 1.225 & -1.184 & -0.280 & -0.145 \\
\hline Consumption & 0.310 & $-1.620 *$ & 0.903 & 1.187 & 1.557 & -1.620 & -1.008 & -0.276 \\
\hline Investment & $0.569 *$ & $-1.493 *$ & 4.471 & 3.281 & 3.224 & -1.493 & 0.139 & 0.172 \\
\hline House prices & $-0.698^{*}$ & $-1.140^{*}$ & 1.986 & 1.986 & 2.062 & -1.140 & -0.252 & -0.089 \\
\hline \multicolumn{9}{|c|}{ Estimation on always binding constraint } \\
\hline Output & & & 1.037 & 1.004 & 1.225 & -1.184 & -0.230 & -0.095 \\
\hline Consumption & & & 0.903 & 0.937 & 1.176 & -1.620 & -0.700 & -0.276 \\
\hline Investment & & & 4.471 & 3.006 & 2.996 & -1.493 & 0.209 & 0.215 \\
\hline House prices & & & 1.986 & 1.159 & 1.185 & -1.140 & -0.330 & -0.170 \\
\hline
\end{tabular}

Notes

Panel A presents skewness statistics for the four variables on data detrended using the Hodrick-Prescott filter (column 'HP filter') and on quarterly growth of the variables ('Growth'). Comparisons of results from the estimated versions of the model with the data are presented in panels $\mathrm{B}$ and $\mathrm{C}$, where the first column represents statistics from the 'Data', the second column statistics from the model with occasionally binding borrowing constraints ('Occas.'), and the third column statistics from a model where these are always binding ('Always'). These results are split into two for the two treatments of the estimation of the model, and the corresponding values for the size and persistence of the shock processes. The top set of results comes from models applying the estimations of these shock parameters on the occasionally binding borrowing constraint version of the model, and the bottom set of results comes from the estimations in the model when the constraint is always binding.

* indicates a skewness statistic that is statistically significantly different from zero with at least $99 \%$ confidence. 
When we look at the standard deviations of macroeconomic variables (panel B of Table 3), the model with occasionally binding borrowing constraints better matches the data, even when the algorithm is minimizing the differences for the model with always binding constraints. The model with occasionally binding borrowing constraints also does substantially better in matching the skewness in macroeconomic data; for all variables in both treatments, the skewness is better estimated in the model with occasionally binding borrowing constraints (panel $\mathrm{C}$ of Table 3). The model predicts less skewness than is present in the data for all of the variables; however, our model allows for only one source of non-linearity, and further, the estimation uses only the size and persistence of shocks in the optimization. On average, the model with occasionally binding borrowing constraints obtains twice as much skewness in the four macroeconomic variables compared to the model where constraints are always binding; this is true across a number of different iterations of the SMM exercise, where the estimation is optimizing over different moments from the data.

\section{Estimation of fiscal multipliers}

We estimate fiscal multipliers for different underlying conditions in both the housing and credit markets. To do this, we utilize the dataset of Romer and Romer (2010) to identify exogenous tax changes (those that are not motivated by short-run growth) and the smooth transitioning vector autoregression (STVAR) methodology from Auerbach and Gorodnichenko (2013). This process estimates the output multiplier from exogenous tax changes under different underlying conditions dictated by a transitioning variable. (Full details of this process can be found in Appendix B.) In our estimates, we test for different conditions in the housing market (determined by the changes in house prices), the credit market (determined by changes in the liabilities to assets ratio) and (for comparison) the business cycle (using growth in GDP per capita). ${ }^{23}$

Results from this exercise are displayed in Table 4 which presents: estimated sixquarter multipliers during a boom (defined as when the transition variable is at its top 20th percentile, representing the highest rates of growth in house prices, credit and GDP, respectively); six-quarter multipliers during 'normal' times (defined as the median of nonboom times); and the $p$-value on the test of statistical significance that the estimated coefficients of the two regimes are different. In all three cases, consistent with our theoretical model, it is observed that multipliers are larger during normal periods than during economic booms. For different states of the housing market and leverage,

TABLE 4

FisCAL MULTIPLIERS: EMPIRICAL ESTIMATES

\begin{tabular}{lrrr}
\hline & LTA & House prices & GDP \\
\hline Six-quarter multiplier: boom & -1.537 & -0.272 & 0.352 \\
Six-quarter multiplier: normal & -2.107 & -1.307 & -1.685 \\
$p$-value for difference & 0.103 & 0.063 & 0.012 \\
\hline
\end{tabular}

Notes

Estimations of output multipliers as a result of exogenous tax movements as identified by Romer and Romer (2010); full details of the process can be found in Appendix B. The six-quarter cumulative multiplier during the boom is defined as that when the transition variable is in the top 20th percentile, and normal times for the median of the remaining values. The final row provides the $p$-value of statistical significance of the difference between the estimated multiplier coefficients for boom and recession. 
multipliers are estimated to be (on average) 50\% smaller during booms compared to normal times; when GDP is booming, tax multipliers are estimated to be positive (a tax cut leading to lower output) compared to negative estimates during normal times. Although these results are not conclusive in themselves, they provide support for the mechanism driving our theoretical results and further contribute to the wealth of evidence discussed. The next subsection compares our theoretical multipliers to those empirical estimates in the existing literature.

\section{Existing evidence on asymmetric fiscal multipliers}

There is some disagreement over the degree of asymmetry in fiscal multipliers. While Owyang et al. (2013) and Ramey and Zubairy (2018) find limited asymmetries in government spending multipliers with respect to slack in the economy, Baum and Koester (2011) find more volatility in spending multipliers using a threshold VAR to estimate a range between 0.36 in good times and 1.04 during recessions. Auerbach and Gorodnichenko (2012, 2013), and Fazzari et al. (2015), on the other hand, find the greatest range in results, with government spending multipliers statistically insignificant from zero at the peak of the business cycle, and 1.6 or greater during recessions. ${ }^{24}$ Both our theoretical and empirical estimates are in the middle of the range of findings in this literature, with differences in fiscal multipliers varying by approximately $40 \%$. It should be noted, though, that we present one theoretical mechanism of potentially many in which multipliers may be non-linear. Indeed, we have shown that through combining non-linearities in the form of the ZLB on interest rates and occasionally binding borrowing constraints, one can get a larger variation in multipliers.

Importantly, our modelling assumptions mean that higher multiplier values are observed during 'normal' times when the borrowing constraint on impatient households always binds; that is, it is not rare to have a more effective policy, and this is not limited to times of crisis. This is indeed documented by Tagkalakis (2008) and Fazzari et al. (2015); the latter find that the USA experienced high multipliers in most periods between 1967 and 2012, and the former presents evidence for heightened effects of fiscal policy for 19 OECD countries between 1970 and 2001 for half of this period.

There are a handful of papers that look at both government spending and tax multipliers collectively, and the variation in estimates between the two can provide support for our results. We find more asymmetry in government spending multipliers compared with tax instruments, but only if transfers (targeted or otherwise) are included in the analysis. For example, our results suggest that average government spending multipliers are $49 \%$ lower with 20 quarters of slack in the impatient borrowing constraint, compared with $33 \%$ lower for taxation instruments. In a model considering the liquidity constraints on households (proxied by the loan-to-value ratios in residential lending), Tagkalakis (2008) finds similar results utilizing data from 19 OECD countries. Spending and taxation multipliers are $95 \%$ and $65 \%$ lower, respectively, during booms (periods of high loan-to-value ratios) compared to recessions. Baum and Koester (2011) apply a threshold structural VAR to data from Germany between 1976 and 2009, and find reductions in government spending multipliers of $43.8 \%$ from recessions to expansions, with the results for changes in tax revenue multipliers not statistically significant. Baum et al. (2012) apply a threshold vector autoregression to data from G7 countries (excluding Italy); however, they do not include transfers in their measure of government spending. They find tax multipliers to be more responsive to the business cycle than government spending multipliers (consistent with our results if we remove transfers from the analysis). 
On average across the G7 countries, spending multipliers are 40.9\% lower during expansions than recessions, whereas tax multipliers are $111.4 \%$ smaller (going from negative multipliers in recessions to mildly positive multipliers in expansions).

\section{CONCLUSIONS}

This paper has shown that fiscal effectiveness can vary substantially across the cycle by developing and presenting a tractable and carefully calibrated DSGE model with endogenously binding borrowing constraints. The key to our framework has been the state-dependent nature of the collateral constraints that are tied to the value of housing wealth-binding in bad times while slack in good times-which, in turn, create state dependence in fiscal multipliers. Moreover, we find that such fiscal asymmetries persist in the long run, better matching the empirical estimates.

Another key aspect of our work has been the rich fiscal structure that we used in our setting, enabling us to explore the state dependence of fiscal policy across a large number of fiscal instruments. The high degree of heterogeneity on the impact of slack in the borrowing constraint on fiscal multipliers across instruments has important interpretations when considering potential non-linearities and subsequent policy recommendations. In our results, transfers (and especially targeted transfers) can have a large non-linear effect depending on the presence of slack in the impatient borrowing constraint as it is these agents who respond to movements in transfers. On the other hand, direct government spending and investment have lower non-linear effects as impatient consumption has less influence on the effectiveness of these policies. The degree and source of state-dependent multipliers are important because they offer more scope for countercyclical fiscal policy; stimulus in a downturn can be repaid with contractionary policy during booms when multipliers are smaller. This provides an additional dimension to policy-making, with crucial implications for the optimal policy design.

\section{APPENDIX A: FURTHER ROBUSTNESS TESTS}

\section{Fiscal policy}

In addition to the further fiscal experiments discussed in Section III, we have also performed experiments similar to those in Table 2 using different shocks altering the underlying conditions of the economy; the results from above are maintained such that multipliers are higher during a recession than in a boom, and the impact of policy itself can change the macroeconomic climate to influence the borrowing constraints on impatient agents. We have also considered different sizes of fiscal shocks than those presented in Table 2, and again the intuition is maintained; the larger the fiscal shock in these experiments, the more scope this policy has on influencing the borrowing conditions of households. We also consider two further extensions to those results in Table 2, that of contractionary fiscal shocks, and when expansionary shocks respond with a lag of one quarter. A negative shock can weaken a boom in the economy, and therefore lead to a shorter horizon over which the borrowing constraint on impatient agents is not binding, thus increasing multipliers during output expansions; the impact with which this occurs is conditional on the extent to which the fiscal policy can influence impatient incomes and house prices. A shock that responds to the change in output with a lag influences the economy as it returns to steady-state values when the borrowing constraint on impatient agents is always binding; however, both of these extensions have only small effects at the margin, and the main intuition is retained (results available on request).

We further consider experiments similar to those in the final subsection of Section II but now including fiscal shocks: lasting for eight quarters (compared with four in the benchmark); lasting 
for four quarters (as in equations (13)) and then followed with persistence after this period (of value 0.8 ); and with higher levels of debt-aversion $\left(\phi_{b, x}\right.$ in equations (13)). Figure A1 presents results for both targeted transfers and labour taxes; results are not sensitive to which fiscal instruments are considered, and these two are chosen for ease of presentation. Although fiscal multipliers in these two extensions vary from those in the benchmark, the difference is limited. In the above two cases, longer lasting shocks lead to higher short-run multipliers as impatient agents play an important role in the transmission mechanism in the case of labour income taxes and transfers. ${ }^{25}$ Higher levels of debt-aversion lead to lower multipliers as the government now more aggressively responds to debt by lowering spending and raising taxes, thus reducing demand. Despite these changes in the sizes of multipliers, however, the asymmetry and state dependence are maintained.
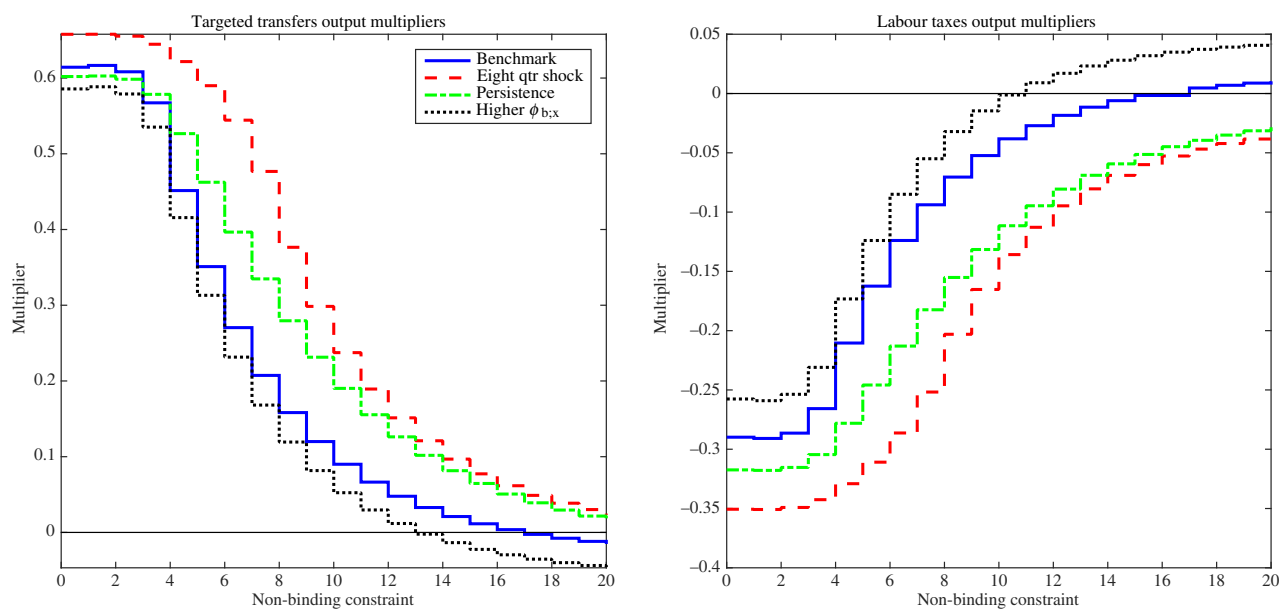

FIGURE A1. Four-quarter cumulative multipliers: fiscal policy extensions.

Notes: Four-quarter cumulative multipliers for targeted transfers and labour taxes under a number of different extensions, as labelled in the legend. 'Benchmark' represents the benchmark results from above. 'Eight qtr shock' represents where fiscal shocks last for eight quarters (in benchmark, fiscal shocks last for four quarters). 'Persistence' represents where there is a four-quarter shock as in the benchmark, and after this there is persistence of 0.8 , such that the value of the shock decays over time. 'Higher $\phi_{b, x}$ ' refers to $\phi_{b, x}=0.4$ (as opposed to 0.2 in the benchmark); this change leads to debt being halved in 18 quarters on average instead of 34 quarters in the benchmark scenario. [Colour figure can be viewed at wileyonlinelibrary.com]

\section{Monetary policy}

We also consider alternative specifications for the Taylor rule and different calibrations of its parameters. Figure A2 presents results for general transfers and labour tax multipliers under various forms of Taylor rule, where again these instruments are used as examples and the results are not sensitive to which fiscal instruments are considered. In general, the results presented in the final subsection of Section II are robust with asymmetric responses to fiscal policy depending on the conditions of the impatient agents' borrowing constraint. The non-linearity of fiscal policy is greater under two scenarios: first, when the response of the monetary authority to higher output is muted $\left(\rho_{y}=0.01\right)$; and second, where the Taylor rule responds to output growth $\left(\mathrm{GDP}_{t} / \mathrm{GDP}_{t-1}\right)$ instead of movements in output from the steady state. When the Taylor rule responds to output growth, multipliers are $54 \%$ and $38 \%$ smaller for government spending and taxation instruments, respectively, when the borrowing constraint is slack for 20 quarters compared to when it is always binding (the corresponding differences were $49 \%$ and $33 \%$ in the benchmark results). In both scenarios, four-quarter multipliers increase significantly (with respect to the benchmark) when the borrowing constraint is binding, or not binding for a relatively short period of time. When this is the case, there is a significant initial increase in output, and a monetary policy that is unresponsive 

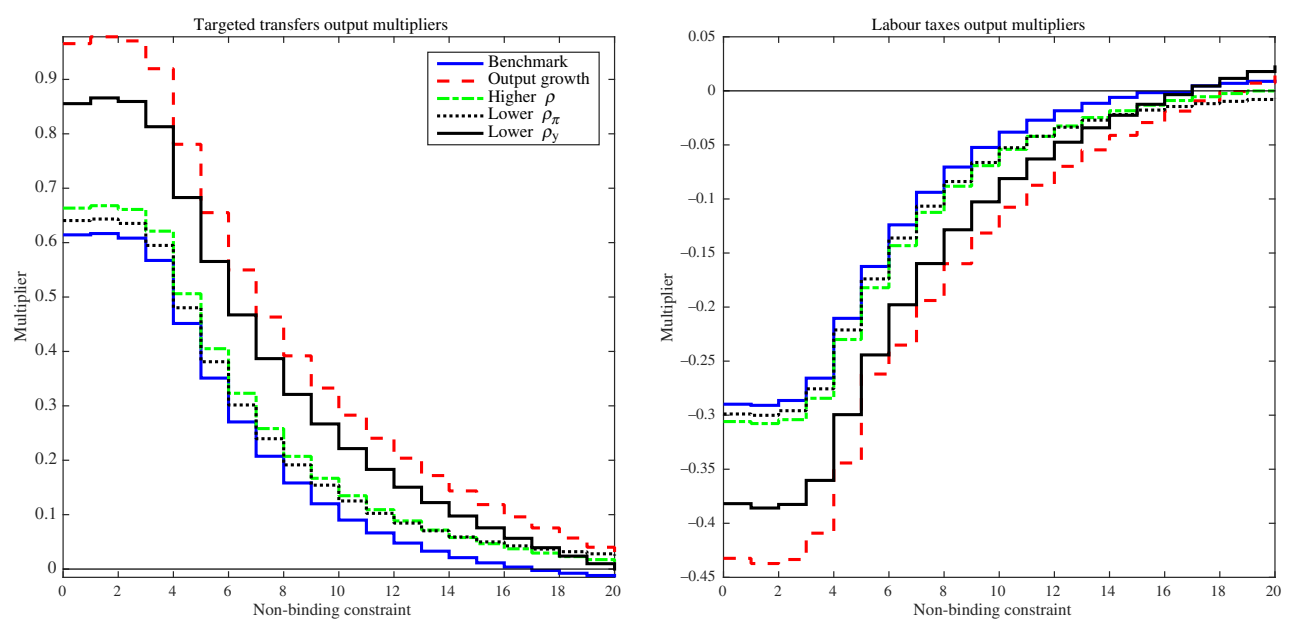

FIGURE A2. Four-quarter cumulative multipliers: Taylor rule extensions.

Notes: Four-quarter cumulative multipliers for targeted transfers and labour taxes under a number of different extensions, as labelled in the legend. 'Benchmark' represents the benchmark results from above. 'Output growth' represents where output growth, as opposed to the deviation of output from the steady state, is in the Taylor rule (10). 'Higher $\rho$ ' represents when the calibration of this parameter is $0.85(0.5509$ in the benchmark). 'Lower $\rho_{\pi}$ ' represents when the calibration of this parameter is 1 (1.7196 in the benchmark). 'Lower $\rho_{y}$ ' represents when the calibration of this parameter is 0.01 (0.0944 in the benchmark). [Colour figure can be viewed at wileyonlinelibrary.com]

to output $\left(\rho_{y}=0.01\right)$ means that the increase in the interest rate is smaller, leading to a smaller crowding out of patient households' consumption and as a result a greater multiplier. A similar profile emerges when the Taylor rule responds to output growth, where changes in the interest rate occur only in the period of growth, whereas there is no change when output is steadily above the steady-state value. With respect to the benchmark, this also implies a smaller response of interest rates and a lower crowding out of patient consumption. For other changes analysed in Figure A2, there are small variations in the sizes of multipliers under different calibrations, but not in the variability of these multipliers as a result of slack in the impatient borrowing constraint.

\section{Model without public employment and employers' social security contributions}

As highlighted in the third subsection of Section II, it is uncommon for DSGE models to contain both employers' social security contributions and public employment, especially a model calibrated to the US economy. This subsection presents results from two separate iterations of the benchmark model above: one with public employment but without social security contributions; and another with no public employment and no employers' social security contributions. Figure A3 presents results for the eight remaining fiscal instruments.

\section{Further sensitivity checks}

Figures A4-A9 present results from a set of further sensitivity checks: changing calibrations of price and wage stickiness; changing other parameter calibrations; changing habit persistence; fixing the stock of housing; with capital income tax on interest from loans and government debt; and adding adjustment costs to government investment. 

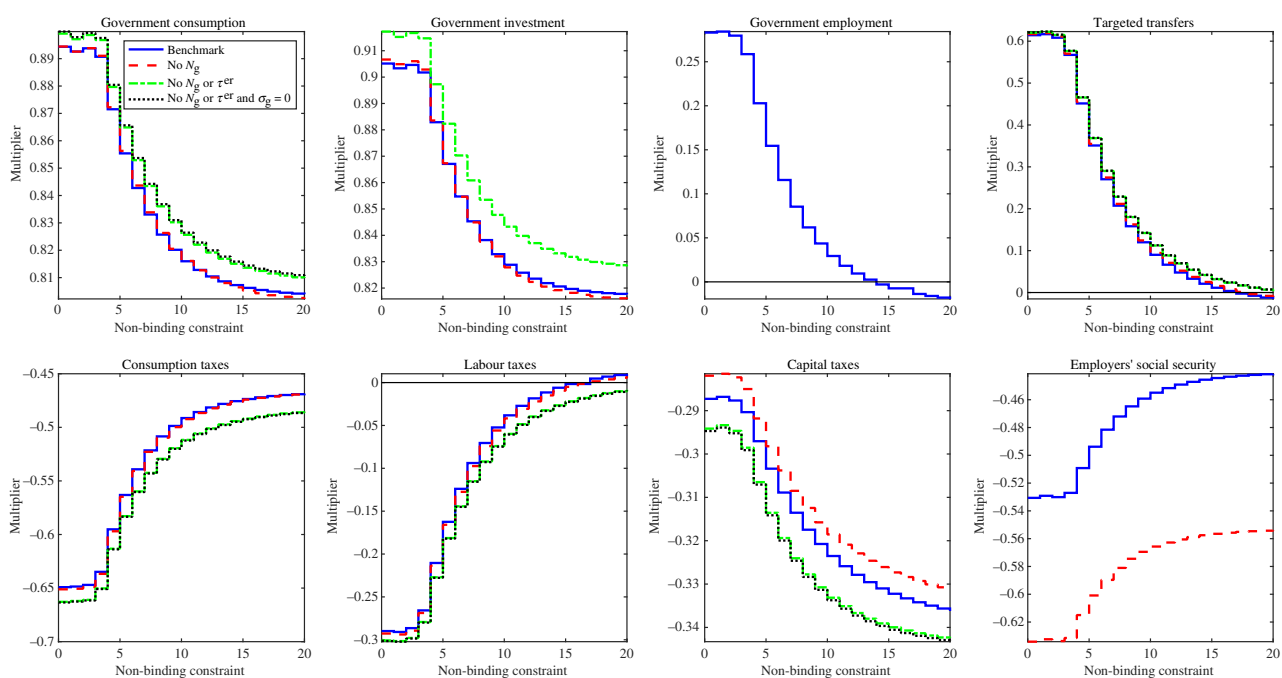

FIGURE A3. Four-quarter cumulative output multipliers: models without public employment and social security contributions.

Notes: Four-quarter cumulative output multipliers for eight fiscal instruments with models which include: the benchmark from above; the benchmark without public employment; the benchmark without public employment and employers' social security contributions; and the benchmark without either employment or employers' social security contributions and where public capital is not productive $\left(\sigma_{g}=0\right)$. [Colour figure can be viewed at wileyonlinelibrary.com
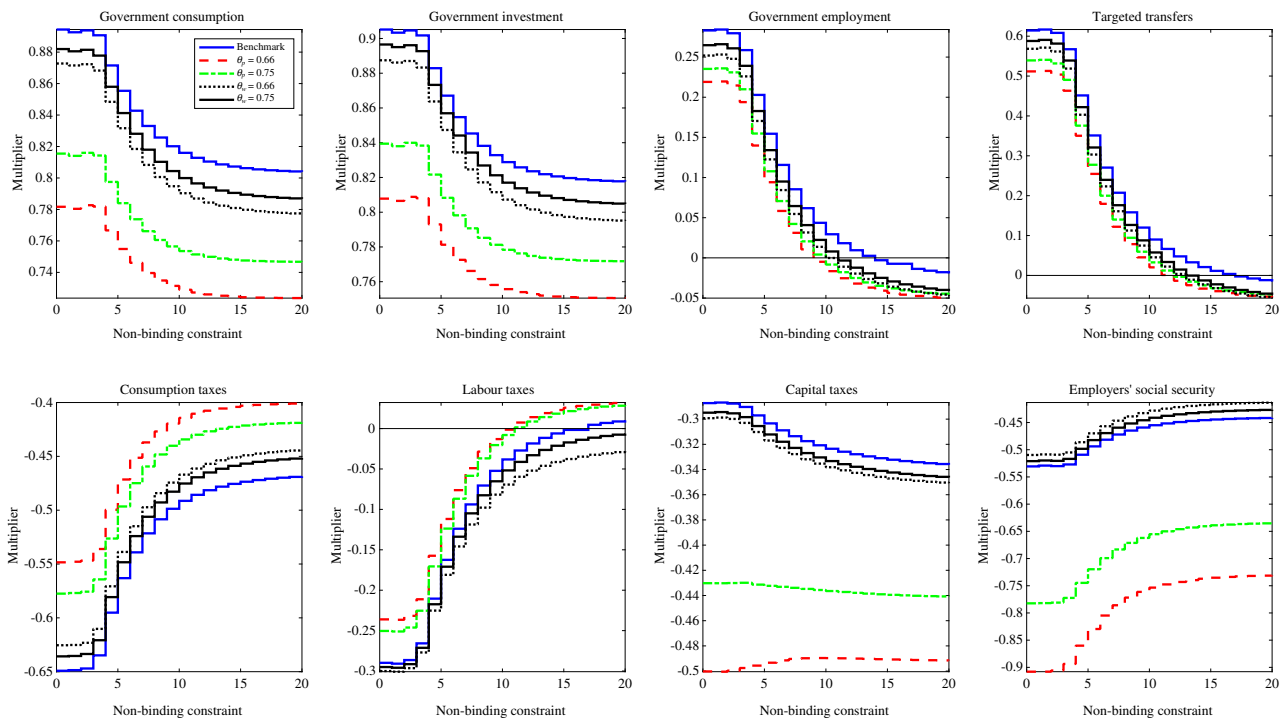

FIGURE A4. Robustness checks: price and wage stickiness.

Notes: Four-quarter cumulative multipliers for eight fiscal experiments under a number of different extensions, as labelled in the legend. [Colour figure can be viewed at wileyonlinelibrary.com 

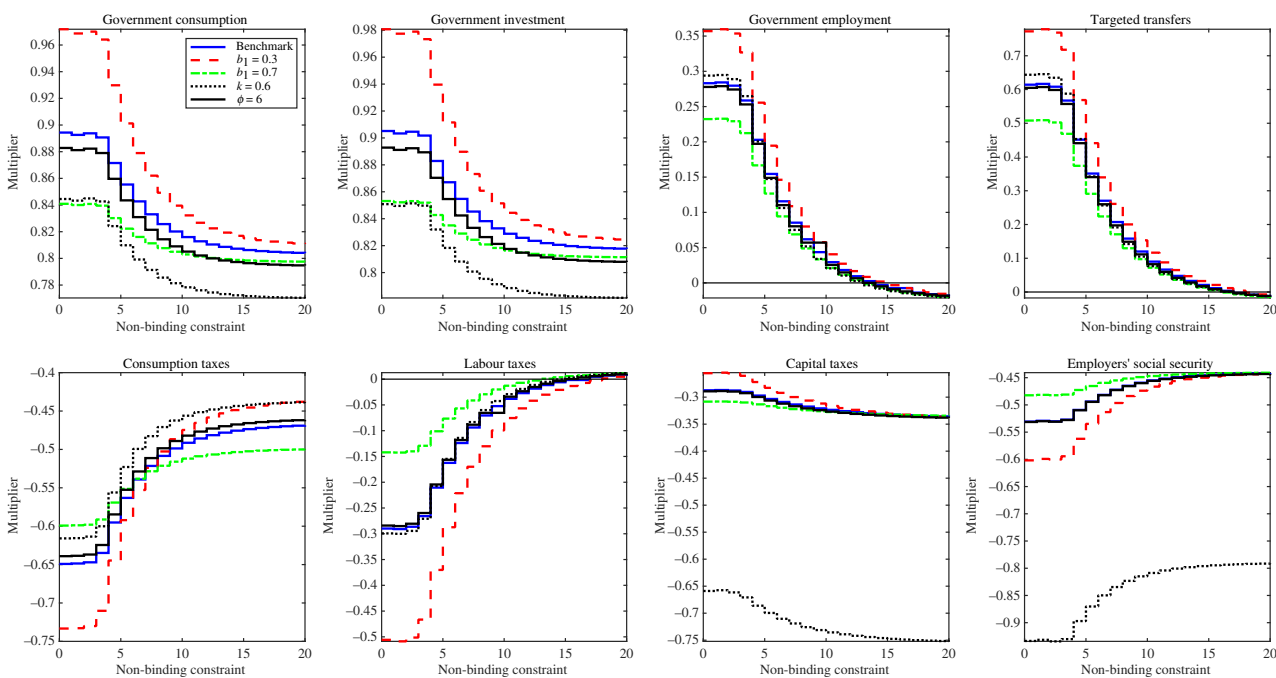

FIGURE A5. Robustness checks: other parameters.

Notes: Four-quarter cumulative multipliers for eight fiscal experiments under a number of different extensions, as labelled in the legend. [Colour figure can be viewed at wileyonlinelibrary.com
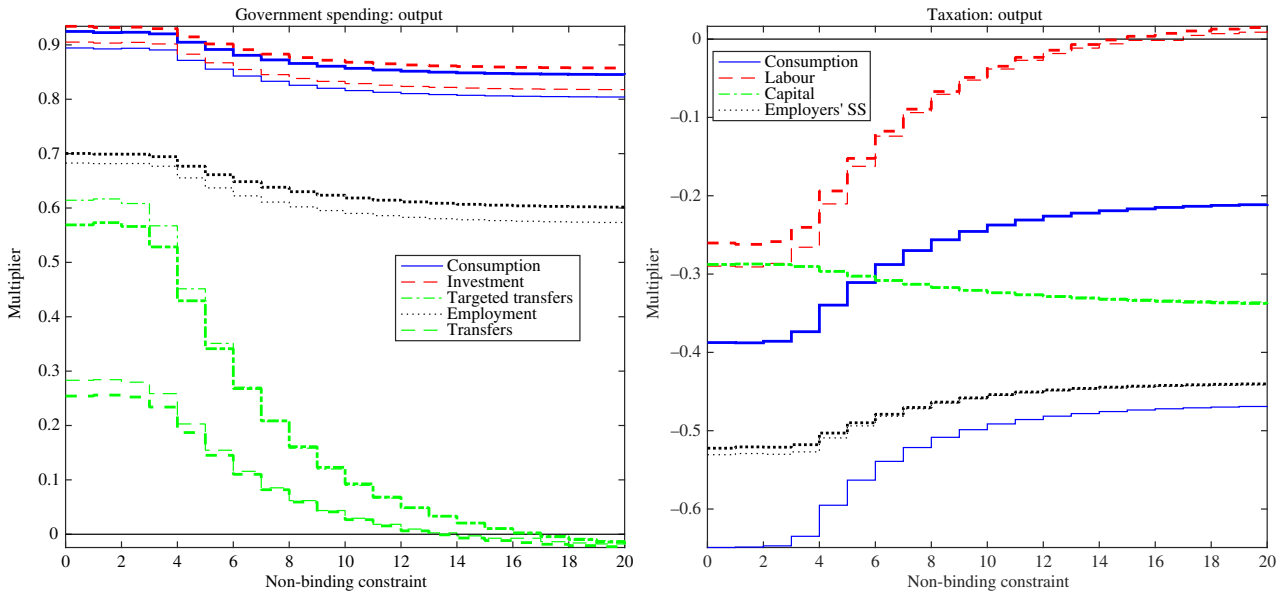

FIGURE A6. Robustness checks: habit persistence.

Notes: Four-quarter cumulative multipliers in nine fiscal experiments for differing horizons over which the borrowing constraint on impatient household does not bind. For each experiment, two sets of results are presented: those with thinner lines are those from the benchmark; those with thicker lines are those where agents' utility functions feature habit persistence with parameter 0.7. [Colour figure can be viewed at wile yonlinelibrary.com 

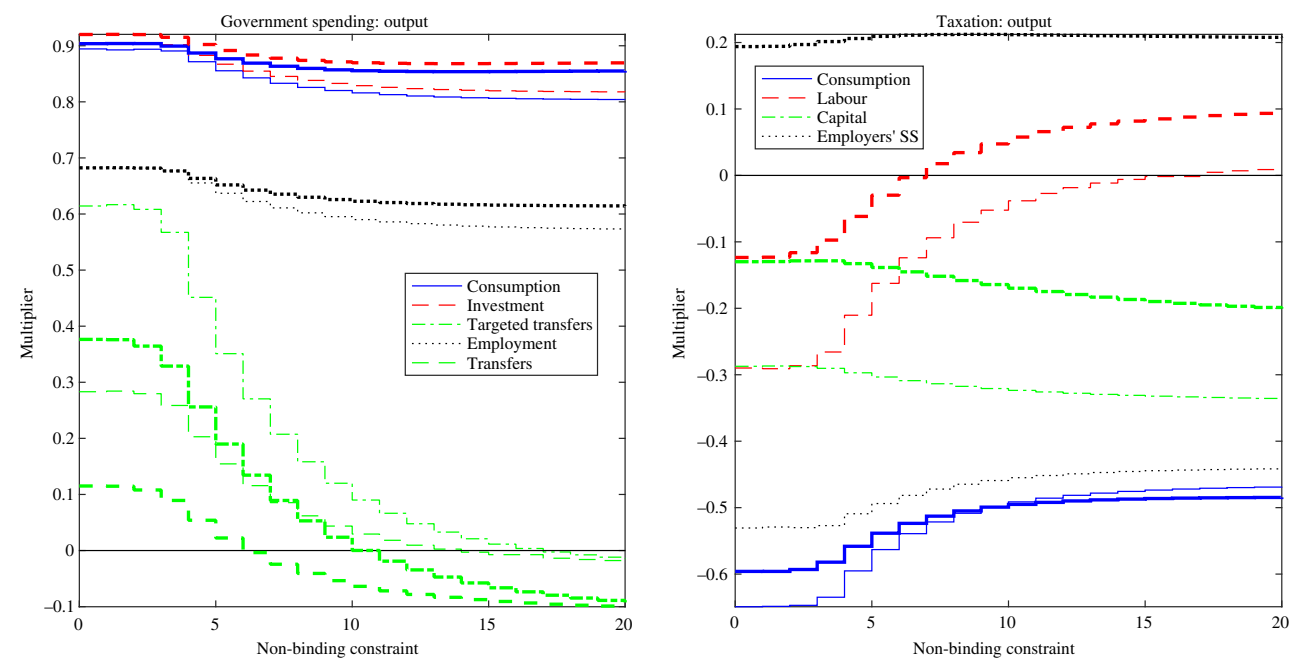

FIGURE A7. Fixed housing stock.

Notes: Four-quarter cumulative multipliers in nine fiscal experiments for differing horizons over which the borrowing constraint on impatient household does not bind. For each experiment, two sets of results are presented: those with thinner lines are those from the benchmark above; those with thicker lines are those where a fixed housing stock is assumed. [Colour figure can be viewed at wileyonlinelibrary.com
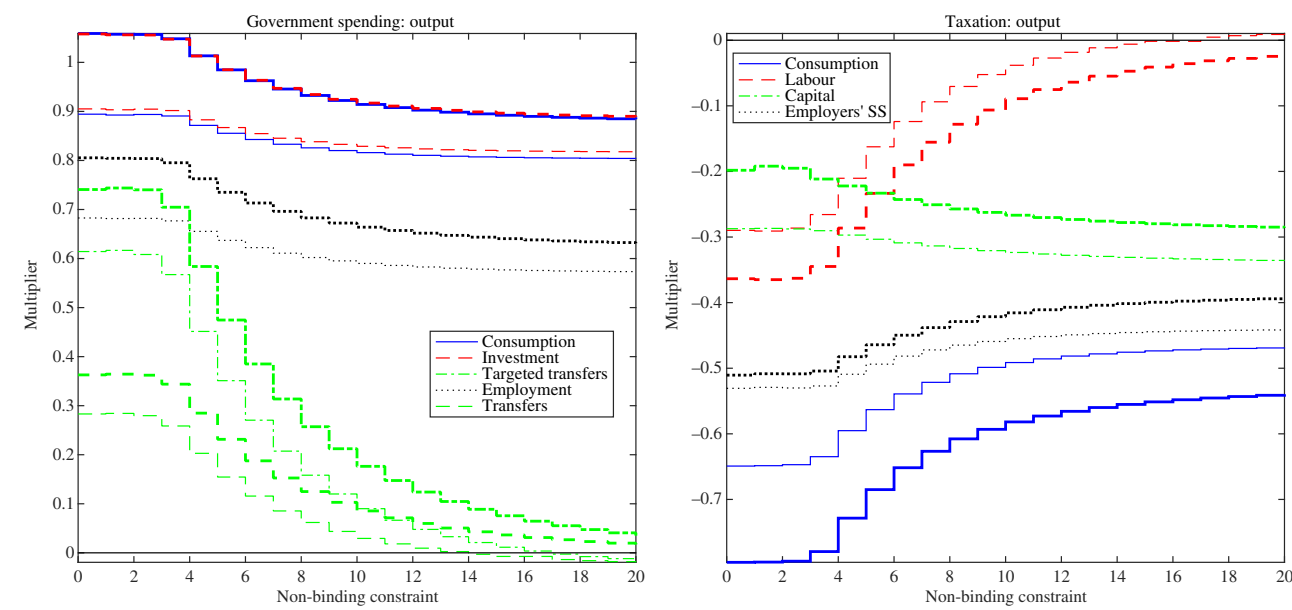

Figure A8. Capital tax on interest income.

Notes: Four-quarter cumulative multipliers in nine fiscal experiments for differing horizons over which the borrowing constraint on impatient household does not bind. For each experiment, two sets of results are presented: those with thinner lines are those from the benchmark above; those with thicker lines are those where a capital tax is charged on interest income from government debt and loans. [Colour figure can be viewed at wileyonlinelibrary.com 

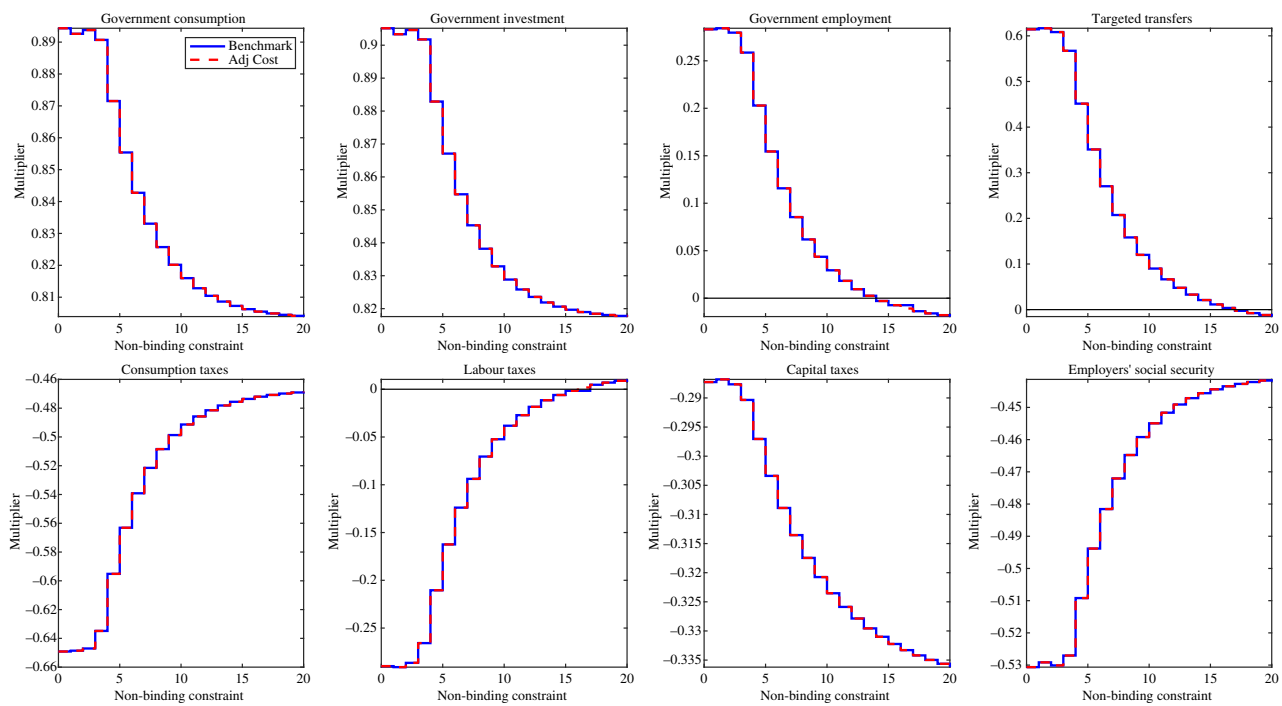

FIGURE A9. Adjustment costs on government investment.

Notes: Four-quarter cumulative multipliers for the eight fiscal experiments for differing horizons over which the borrowing constraint on impatient household does not bind. For each experiment, two sets of results are presented: the benchmark above and where an adjustment cost to government investment is imposed, similar to that on private investment (with the same calibration). [Colour figure can be viewed at wileyonlinelibrary.c om]

\section{APPENDIX B: EMPIRICAL ESTIMATION: TECHNICAL}

This section provides the technical details for the empirical estimation discussed in the third subsection of Section IV. We utilize the work of Romer and Romer (2010), who develop a dataset for classifying US tax changes into those that are endogenous to the business cycle (those that seek to influence short-term growth) and those that are exogenous (performed for reasons beyond shortrun growth) by analysing announcements about the policies (for example, presidential speeches, executive-branch documents and congressional reports). Utilizing this dataset and using the smooth-transitioning model developed in Auerbach and Gorodnichenko (2013), we estimate the specification

$$
X_{t}=\alpha_{h}+F\left(z_{t}\right)\left[\Pi_{R}(L) X_{t-1}+\Phi_{R} d_{t}\right]+\left(1-F\left(z_{t}\right)\right)\left[\Pi_{E}(L) X_{t-1}+\Phi_{E} d_{t}\right]+u_{t},
$$

$$
F\left(z_{t}\right)=\frac{\mathrm{e}^{-\gamma z_{t}}}{1+\mathrm{e}^{-\gamma z_{t}}}, \quad \gamma>0
$$

where $X$ is the macroeconomic outcome of interest (output in our case), $\Pi_{i}$ and $\Phi_{i}$ are lag polynomials for periods of expansions $(i=E)$ and recession $(i=R), F\left(z_{t}\right)$ is the transition function where $z_{t}$ is a variable over which multipliers are allowed to vary, and $d_{t}$ are the exogenous tax shocks whose size, timing and motivation are established from narrative records. We use three different measures for our transitioning variable in three separate estimations: house price inflation (using the all-transaction house price index from FRED); the ratio of household liabilities to assets (from the US Flow of Funds from the Federal Reserve); and cyclical growth in GDP per capita, identified using the Hodrick-Prescott filter (as in Auerbach and Gorodnichenko 2013). Following Auerbach and Gorodnichenko (2013), we use six-quarter moving averages of these variables, and we use $\gamma=1.5$. Following Romer and Romer (2010), we estimate equation (1) using 12 lags for the exogenous tax shock, and then apply bootstrapping to estimate standard errors in the cumulative output multipliers. 
TABLE A1

Correlation Coefficients: Liabilities-to-Assets, House Prices And GDP

\begin{tabular}{lccr}
\hline & LTA & House prices & GDP \\
\hline A. Levels & & & \\
LTA & 1.000 & 0.942 & 0.963 \\
House prices & & 1.000 & 0.948 \\
GDP & & & 1.000 \\
B. Growth rates & 1.000 & -0.033 & 0.062 \\
LTA & & 1.000 & 0.073 \\
House prices & & & 1.000 \\
GDP & 1.000 & 0.122 & 0.043 \\
C. Transitioning variable & & 1.000 & 0.245 \\
LTA & & & 1.000 \\
House prices & & & \\
GDP & & & \\
\hline
\end{tabular}

Notes

Correlation coefficients between liabilities-to-assets (LTA), house prices and GDP per capita in levels (panel A), growth rates (panel $\mathrm{B}$ ), and once the variables have been transformed into the transition variable (panel C) as described in specification (A1).

The empirical estimates presented in Table 4 are in line with the original Romer and Romer (2010) paper, which finds tax multipliers of 1.5 after six quarters. Note that the way in which these multipliers are calculated differs from what we do in the theoretical analysis in the paper. Whereas in our paper we divide the cumulative change in output by the cumulative change in the fiscal variable over the time period against which the multiplier is measured, it is common in the empirical literature looking at narrative changes to use the tax change in the first quarter (and not the cumulative change in taxes over a number of quarters) as the denominator. This explains the difference between the empirical estimates and the theoretical multiplier values in the paper.

Due to the number of observations, it is not possible to estimate fiscal multipliers under each of the three transitioning variables simultaneously, and we estimate equation (1) for each of the transitioning variables individually. Table A1 presents correlation coefficients across these three variables and presents a high level of positive comovement between them in levels (panel A). That is, high levels of output are associated with high levels of liabilities to asset and house prices; however, when these variables are presented in growth rates (panel B), correlation diminishes, with coefficients not significantly different from zero. Finally, when these statistics are transformed into the smooth transitioning variables for use in specification (1), there is moderate positive comovement (panel C), but much lower than those presented in levels.

In addition to our benchmark specifications in the third subsection of Section IV, we have conducted sensitivity tests to ensure that the results are robust to: different values of $\gamma$; different lags of $d_{t}$ in the specification; and different measures for both house prices in the USA, and the loans-toassets ratio. In each case, the main message from the benchmark results is maintained, that fiscal multipliers are larger during 'normal' times compared to boom periods in the housing market, credit or business cycles.

\section{ACKNOWLEDGMENTS}

We are grateful to the editor and two anonymous referees for very helpful comments. We also thank participants at the European Monetary Forum workshop, at the University of York, 17 March 2017, the Money, Macro Finance 2017 Annual Conference at King's College, London, 7-9 September 2017, the 2018 Royal Economic Society Annual Conference at the University of Sussex, 26-28 March 2018, the Warsaw International Economic Meeting 2018 at the University of Warsaw, 3-5 July 2018, and the Conference on Growth and Business Cycles in Theory and Practice 
at the University of Manchester, 4-5 July 2018, for comments and suggestions. The usual disclaimer applies.

\section{NOTES}

1. Similarly, the countercyclical nature of financial intermediation and its role in the state dependence of fiscal policy is also explored by Faria-e Castro (2017) in a paper studying the effectiveness of the US fiscal policy during the global financial crisis. It is shown that following the global financial crisis, the fall in private consumption would have been worse by a third in the absence of the fiscal stimulus in the USA.

2. The endogenized production of housing brings the model closer to that of Iacoviello and Neri (2010) and Alpanda and Zubairy (2016) (among others), and provides a more realistic framework of the economy whereby the housing stock can vary with the macroeconomic climate and can further have a feedback effect on the economy. We test the sensitivity of our results to this assumption, which is discussed in the final subsection of Section III.

3. The scaling factor $\Gamma_{c}^{P}=\left(1-h^{P}\right) /\left(1-\beta h^{P}\right)$ ensures, as in Iacoviello and Neri (2010), that the steady state is not affected by habit persistence in consumption. The utility function does not allow for habit persistence in housing; in a model similar to ours, Iacoviello and Neri (2010) estimate habit persistence in housing and find estimates insignificant from zero.

4. Note that when we combine the net purchases of government bonds $B_{t}-B_{t-1} / \pi_{t}$ with the income from these bonds $\left(\left(R_{t-1}-1\right) / \pi_{t}\right) B_{t-1}$, the result would have $B_{t}$ on one side of the budget constraint and $R_{t-1} B_{t-1} / \pi_{t}$ on the other (with a similar condition for loans), as presented in equation (3).

5. Note that in this specification, taxes on capital income are applied to dividends and income on physical capital, and not on income generated from holdings in government debt. This is in line with much of the existing literature (see, for example, Leeper et al. 2010a,b; Trabandt and Uhlig 2011; Drautzburg and Uhlig 2015); we test and discuss the sensitivity of our results to this assumption in the final subsection of Section III.

6. Note that this formulation of GDP has three components: the total demand for the non-residential good $Y_{t}$; investment in housing $q H I_{t}$; and the wage cost of public sector employment $\left(1+\tau_{t}^{e r}\right)\left(w_{t}^{P} N_{g, t}^{P}+w_{t}^{I} N_{g, t}^{I}\right)$, which is equal to the output of public sector.

7. We model employment by the government to be unproductive in that the output from such employment enters neither the utility functions of agents nor the production functions of producers. The monetary value of government employment, through the payment of wages, is added to the gross domestic product of the economy.

8. This characterization is increasingly common in the literature; see, for example, Coenen et al. (2012).

9. Note that in the steady state, the borrowing constraint of impatient households is binding: $\lambda^{b}=1-\gamma / \beta>0$ as $\gamma<\beta$. We impose the restriction $\lambda_{t}^{b} \geq 0$, implying that impatient agents either wish to borrow $\left(\lambda_{t}^{b}>0\right)$ or are indifferent between borrowing and saving $\left(\lambda_{t}^{b}=0\right)$; a similar restriction is also adopted in Guerrieri and Iacoviello (2017).

10. Although we model the source of non-linearity as the occasionally binding collateral constraints facing the impatient agents, it is likely that the proportion of constrained agents will also be higher in downturns, hence increasing the likelihood of a sharp response to fiscal shocks. Our robustness checks indeed indicate that the greater the fraction of impatient agents, the higher the fiscal multipliers in recessions and hence the greater fiscal policy effectiveness. It is therefore straightforward to establish that fiscal asymmetry between the booms and recessions will be greater in a model with an endogenously determined share of creditconstrained agents. Developing such a framework would be an important avenue for future research.

11. In order to get the borrowing constraint not binding for a greater number of periods, we increase the size of the housing preference shock. A two (eight) quarter period of slack in the borrowing constraint requires a shock leading to an on impact increase in the house price of $0.5 \%(2.3 \%)$. Given that an estimated one standard deviation housing preference shock leads to an approximate increase of $2 \%$ in the house price in Guerrieri and Iacoviello (2017), it is clear that the magnitude of the required shock to ensure the slackness of the borrowing constraint is well within the range observed in the data. Guerrieri and Iacoviello (2017), for example, in an estimated version of their model, find the borrowing constraint on impatient agents to have been slack between 1998 and 2006.

12. For government spending instruments $\left(G_{C}, I_{G}, N_{g}, \mathrm{TR}\right)$, we set each shock such that the change is equal to $0.01 \%$ of steady-state output. To ensure comparability of multipliers across fiscal instruments, we shock tax rates such that the change in the steady-state tax revenue is also equal to $0.01 \%$ of steady-state output. This size of shock ensures that the horizon over which the borrowing constraint on impatient agents is not binding is unaffected.

13. All the data used to calculate the steady-state shares are taken from the US Bureau of Economic Analysis (2018). Data on private consumption expenditure, non-residential investment, and residential investment are from BEA Table 1.1.5. Data on public consumption, investment and transfers are taken from Table 3.1. Data on public capital, private residential and non-residential capital are from Table 1.1. Data on physical 
capital in the residential production sector are taken from Table 3.1ESI. Data used to calculate the share of employees working in the public sector are taken from Table 6.4B.

14. None of these models includes public employment, and in all three the level of transfers is fixed through the calibration of other parameters.

15. The inclusion of either employers' social security contributions or public employment (and, to a lesser extent, government investment) is an uncommon assumption in the literature. Therefore we test the sensitivity of our results to a model that does not include these; see Appendix A for further details.

16. Coenen et al. (2012) compute fiscal multipliers across seven instruments for a number of models used by policy institutions.

17. This is in line with Guerrieri and Iacoviello (2017), who show that the borrowing constraint was slack in the USA between 1998 and 2006, and the subsequent housing collapse led to tightening of constraints, which exacerbated the recession of 2008-9.

18. At the margin, there is some non-monotonicity in the movements of multipliers as the borrowing constraint on the impatient does not bind for longer horizons; that is, for some fiscal instruments, we can see a slight increase in multipliers when the borrowing constraint is not binding for two quarters versus to when it is always binding. This non-monotonicity is negligible (observed at the third decimal place or higher) and is due to the fiscal experiments in equations (13) being fixed for four quarters. When the constraint on impatient agents is not binding for two quarters (say), half of the fiscal shock is in this period, and half is not. When this occurs, impatient agents can increase their consumption by more in periods three and four, due to lower interest payments in period two, when the households were not borrowing as much as they could have.

19. Further, these MPC values are higher for those who are credit-constrained, those who do not have a buffer of savings, and those who have higher debt-to-income ratios, all reconciling with the characteristics of the impatient in our model.

20. This is further supported in Jensen et al. (2020) through illustrating that both the state-level variance of the Great Recession and the skewness of output are correlated with state-level debt-to-income ratios.

21. Jensen et al. (2020) discuss how SMM estimation is particularly useful for DSGE models with non-binding borrowing constraints.

22. Following Abbritti and Fahr (2013), we use the standard deviations from Hodrick-Prescott detrended data and the skew from growth rates (as in Jensen et al. 2020); results are not sensitive to this and are robust to different definitions. We apply the Matlab function fminsearchbnd to perform the optimization. To calculate moments, we used the following data: the logarithm of GDP, consumption, private investment and residential investment, where all the data are from National Income and Product Accounts (NIPA) Table 1.1.5 and are first divided by civilian non-institutional population over 16 (variable named 'LNU00000000Q' by the US Bureau of Labor Statistics (2018)), and the GDP deflator (NIPA Table 1.1.4, US Bureau of Economic Analysis (2018)); relative house prices, where house price is All-Transactions House Price Index for the USA (variable named 'USSTHP' by the US Federal Housing Finance Agency (2018)) divided by the GDP deflator; inflation is given by log difference of the GDP deflator.

23. It should be noted that the use of loans-to-value is an imperfect measure of the strength of the credit market as higher values may represent higher availability of credit or a significant drop in the value of assets.

24. Ramey and Zubairy (2018) suggest that the results from Auerbach and Gorodnichenko (2013) are sensitive to the way in which impulse response functions are derived, something that is less straightforward in nonlinear models. When using a different method to derive these impulse responses, lower levels of asymmetries are found in Ramey and Zubairy (2018).

25. For the remaining fiscal instruments, where impatient households play a relatively less significant role in the transmission mechanism, the negative wealth effect dominates and the more persistent action of the fiscal authority results in smaller multipliers, and the impact on the variability of these over the business cycle is very limited.

\section{REFERENCES}

AbBritti, M. and FAHR, S. (2013). Downward wage rigidity and business cycle asymmetries. Journal of Monetary Economics, 60(7), 871-86.

Alpanda, S. and Zubairy, S. (2016). Housing and tax policy. Journal of Money, Credit and Banking, 48(2-3), 485-512.

Auerbach, A. J. and Gorodnichenko, Y. (2012). Measuring the output responses to fiscal policy. American Economic Journal: Economic Policy, 4(2), 1-27.

_- and (2013). Fiscal multipliers in recession and expansion. In A. Alesina and F. Giavazzi (eds), Fiscal Policy after the Financial Crisis. Chicago, IL: University of Chicago Press, pp. 63-98.

BachmanN, R. and Sims, E. R. (2012). Confidence and the transmission of government spending shocks. Journal of Monetary Economics, 59(3), 235-49.

BAum, A. and Koester, G. (2011). The impact of fiscal policy on economic activity over the business cycle: evidence from a threshold VAR analysis. Technical Report, Deutsche Bundesbank Research Centre.

Economica

(C) 2020 The Authors. Economica published by John Wiley \& Sons Ltd on behalf of London School of Economics and

Political Science 
Poplawski-Ribeiro, M. and Weber, A. (2012). Fiscal multipliers and the state of the economy. Technical Report, International Monetary Fund.

Bunn, P., Le Roux, J., Reinold, K. and Surico, P. (2018). The consumption response to positive and negative income shocks. Journal of Monetary Economics, 96, 1-15.

CAlvo, G. (1983). Staggered prices in a utility-maximizing framework. Journal of Monetary Economics, 12(3), 383-98.

Canzoneri, M., Collard, F., Dellas, H. and Diba, B. (2016). Fiscal multipliers in recessions. Economic Journal, 126(590), 75-108.

Christelis, D., Georgarakos, D., Jappelli, T., Pistaferri, L., Van Rooij, M., et al. (2019). Asymmetric consumption effects of transitory income shocks, The Economic Journal, 129(622), 2322-234.

Coenen, G., Erceg, C. J., Freedman, C., Furceri, D., Kumhof, M., Lalonde, R., Laxton, D., Lindé, J., Mourougane, A., Muir, D., Mursula, S., De Resende, C., Roberts, J., Roeger, W., Snudden, S., Trabandt, M. and IN 'T VELD, J. (2012). Effects of fiscal stimulus in structural models. American Economic Journal: Macroeconomics, 4(1), 22-68.

Curdia, V. and Woodford, M. (2010). Credit spreads and monetary policy. Journal of Money, Credit and Banking, 42(S1), 3-35.

Drautzburg, T. and Uhlig, H. (2015). Fiscal stimulus and distortionary taxation. Review of Economic Dynamics, 18(4), 894-920.

ERCEG, C. and LindÉ, J. (2014). Is there a fiscal free lunch in a liquidity trap? Journal of the European Economic Association, 12(1), 73-107.

FARIA-E CASTRO, M. (2017). Fiscal multipliers and financial crises. Norges-Bank Technical Report.

Fazzari, S. M., Morley, J. and PanovskA, I. (2015). State-dependent effects of fiscal policy. Studies in Nonlinear Dynamics \& Econometrics, 19(3), 285-315.

Galí, J., López-SAlido, J. D. and VAllés, J. (2007). Understanding the effects of government spending on consumption. Journal of the European Economic Association, 5(1), 227-70.

Guerrieri, L. and Iacoviello, M. (2015). OccBin: a toolkit for solving dynamic models with occasionally binding constraints easily. Journal of Monetary Economics, 70, 22-38.

- and (2017). Collateral constraints and macroeconomic asymmetries. Journal of Monetary Economics, 90, 28-49.

IACOVIELlo, M. (2005). House prices, borrowing constraints, and monetary policy in the business cycle. American Economic Review, 95(3), 739-64.

_- and NERI, S. (2010). Housing market spillovers: evidence from an estimated DSGE model. American Economic Journal: Macroeconomics, 2(2), 125-64.

Jensen, H., Petrella, I., Ravn, S. H. and Santoro, E. (2020). Leverage and deepening business cycle skewness. American Economic Journal: Macroeconomics, 12(1).

Leeper, E. M., Plante, M. and Traum, N. (2010a). Dynamics of fiscal financing in the United States. Journal of Econometrics, 156(2), 304-21.

- WAlker, T. B. and YANG, S.-C. S. (2010b). Government investment and fiscal stimulus. Journal of Monetary Economics, 57(8), 1000-12.

Michaillat, P. (2014). A theory of countercyclical government multiplier. American Economic Journal: Macroeconomics, 6(1), 190-217.

OWyang, M. T., RAmey, V. A. and Zubairy, S. (2013). Are government spending multipliers greater during periods of slack? Evidence from twentieth-century historical data. American Economic Review, 103(3), 12934.

RAMEY, V. A. and ZubAiry, S. (2018). Government spending multipliers in good times and in bad: evidence from US historical data. Journal of Political Economy, 126(2), 850-901.

RAtTo, M., RoEger, W. and IN 'T VELD, J. (2009). QUEST III: an estimated open-economy DSGE model of the Euro area with fiscal and monetary policy. Economic Modelling, 26(1), 222-33.

Romer, C. D. and Romer, D. H. (2010). The macroeconomic effects of tax changes: estimates based on a new measure of fiscal shocks. American Economic Review, 100, 763-801.

SMETs, F. and Wouters, R. (2007). Shocks and frictions in US business cycles: a Bayesian DSGE approach. American Economic Review, 97(3), 586-606.

Tagkalakis, A. (2008). The effects of fiscal policy on consumption in recessions and expansions. Journal of Public Economics, 92(5), 1486-508.

Trabandt, M. and Uhlig, H. (2011). The Laffer curve revisited. Journal of Monetary Economics, 58(4), 30527.

Traum, N. and YANG, S.-C. S. (2015). When does government debt crowd out investment? Journal of Applied Econometrics, 30(1), 24-45. 
US Bureau of ECONOMiC ANAlysis (2018). BEA data; available online at \#https://www.bea.gov/data \# (accessed \#21 \#February \#2020).

US Bureau of Labor Statistics (2018). Data available online at \#https://www.bls.gov \#(accessed \#21 \#February \#2020).

US Federal Housing FinAnce Agency (2018). Data available online at \#https://www.fhfa.gov \#(accessed \#21 \#February \#2020).

\title{
SUPPORTING INFORMATION
}

Additional Supporting Information may be found in the online version of this article:

\author{
I Production sector \\ II Households \\ III Fiscal policy \\ IV Monetary policy \\ $\mathrm{V}$ Market equilibrium and market clearing \\ VI Steady-state
}

